
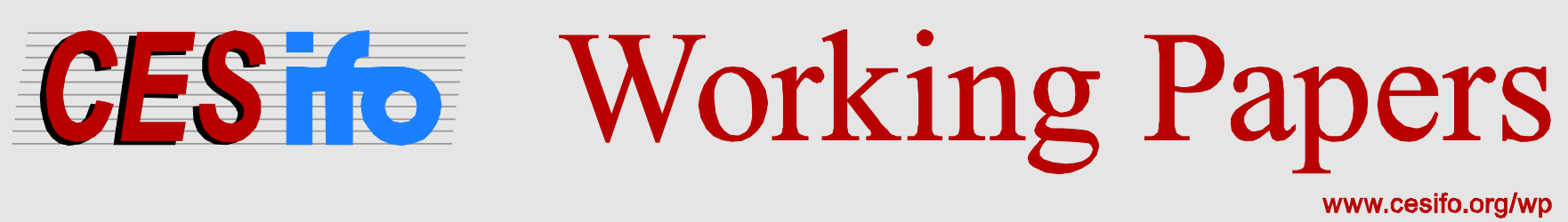

\title{
Investment Effects of Wealth Taxes under Uncertainty and Irreversibility
}

\author{
Rainer Niemann \\ Caren Sureth-Sloane
}

CESIFO WORKING PAPER NO. 5610

CATEgory 1: Public FinANCE

NOVEMBER 2015
An electronic version of the paper may be downloaded
- from the SSRN website: WWw.SSRN.com
- from the RePEc website: $\quad$ www.RePEc.org
- from the CESifo website: www.CESifo-group.org/wp




\title{
Investment Effects of Wealth Taxes under Uncertainty and Irreversibility
}

\begin{abstract}
The growing dissatisfaction with perceived distributional inequality and budgetary constraints gave rise to a discussion on the (re-)introduction of wealth taxes. Wealth taxes are typically levied on private wealth, in some countries also on corporate wealth. To avoid misleading statements concerning possible distributional consequences of wealth taxes, preceding analyses of the economic and particularly investment effects are necessary. As investments drive job creation, tax-induced changes in investment timing may significantly affect the income and wealth distribution. We analyze the impact of wealth taxes on investment timing under uncertainty and irreversibility and the propensity to carry out risky projects. Using a Dixit/Pindyck type real options model we find that wealth taxes have real effects. This means that higher wealth tax rates can either stimulate or depress the propensity to invest in risky projects. We find that apparently paradoxical wealth tax effects (accelerated investment due to higher wealth tax rates) are more likely for low interest rates and for high-risk investments. Using either historical cost or fair value accounting may affect investment timing ambiguously. Thus, the design of wealth taxes is crucial for the resulting delay or acceleration of investment. Although our model takes an individual perspective, our findings are also relevant for the current tax policy discussion on the introduction of wealth taxes. Our results indicate that wealth taxes are particularly harmful for specific classes of investments, for example low-risk investments.
\end{abstract}

JEL-Codes: H210, H250.

Keywords: wealth tax, investment decisions, real options, timing flexibility, uncertainty, irreversibility.

\author{
Rainer Niemann \\ Karl-Franzens-University \\ Graz / Austria \\ niemann@uni-graz.at
}

\author{
Caren Sureth-Sloane \\ University of Paderborn \\ Paderborn / Germany \\ caren.sureth@uni-paderborn.de
}

We thank Michael Stimmelmayr, Martin Jacob, Richard Sansing, Regina Ortmann and the participants of the TAF Research Seminar in December 2014 in Paderborn, the participants of the SOWI Research Seminar in January 2015 in Graz, of the Spring meeting of the Tax Section of the German Academic Association for Business Research in March 2015 in Passau, of the 1st Berlin-Vallendar Conference on Tax Research in July 2015 in Berlin, and of the 9th Norwegian-German Seminar on Public Economics in November 2015 in Munich. The usual disclaimer applies. 


\section{Investment Effects of Wealth Taxes under Uncertainty and Irreversibility}

\section{Introduction}

The tight fiscal constraints in several European countries as well as the growing dissatisfaction with perceived distributional inequality (for example, OECD 2015) gave rise to a discussion on the (re-)introduction of wealth taxes. ${ }^{1}$ To avoid misleading statements concerning possible distributional consequences of wealth taxes, preceding analyses of the economic and particularly investment effects are necessary. As investments drive job creation, tax-induced changes in investment may significantly affect the income and wealth distribution. If wealth taxation affects investment decisions in an unexpected way, forecasts of distributional effects of wealth taxes are necessarily flawed. We investigate the investment timing effects of individual or corporate wealth taxes under uncertainty and irreversibility because investment timing is an important indicator for investors' propensity to carry out risky projects. The goal of our paper is to figure out whether wealth taxes have real effects and under what conditions wealth taxes foster or hinder risky investments.

Focussing on tax rate effects in the first place, we find that an increase in the wealth tax rate can either delay (hinder) or accelerate (foster) risky investments. In terms of risk taking this result implies that higher wealth tax rates can either stimulate or depress the propensity to invest in risky projects. A similar ambiguous result can be derived for increased wealth taxation of the default alternative (risk-free financial investment). Furthermore, for sufficiently low tax values of a project due to a low initial tax value or high depreciation rates for wealth tax purposes, higher wealth tax rates surprisingly

\footnotetext{
${ }^{1}$ The effects of wealth taxes have been controversally discussed in previous years. See, e.g., Balogh (1964), Stiglitz (1969), Mieszkowski (1972), Thurow (1972), Bentick (1979), Mills (1981), Brennan and Nellor (1982), Michalos (1988), Bird (1991), Burbridge (1991), Davies (1991), Mintz (1991), and Kocherlakota (2005).
} 
can accelerate investment. Higher wealth taxation of financial investments in comparison to real investments can delay real investment if the wealth tax rate is sufficiently high. We find that such apparently paradoxical wealth tax effects - accelerated investment upon a wealth tax rate increase - are more likely for low interest rates and for high-risk investments. As a change in investments following an increase in wealth taxes will affect profits and job creation and may increase distributional inequality our results indicate that tax politicians who strive to reduce inequality need detailed information about the effects of wealth taxation on different types of investment projects. Tax legislators should be aware that the effects depend on the expected development of pre-tax profits as well as the valuation of assets for income and wealth tax purposes.

In contrast to tax rate effects we find that valuation effects are unambiguous: higher initial or subsequent valuation of assets for wealth tax purposes always delays investment. A tax legislator whose intention is to encourage risk taking should define a relatively small tax base. Moreover, it is ambiguous whether historical cost valuation or fair value accounting accelerate investment.

Our findings are relevant for individual investors as well as for the current tax policy discussion on whether or not to (re-)introduce a general wealth tax. For example, the IMF suggested the introduction of wealth taxes in developed countries in various recent studies (IMF 2013, IMF 2014). Furthermore, Atkinson (1971), Piketty, and Saez (2003), Saez and Veall (2005), Atkinson, Piketty, and Saez (2011) and more recently Piketty (2014) received a lot of attention with descriptives of the development of the capital/income ratio over time in many countries. As a consequence, he raises the claim for wealth taxes. Although this work has been heavily criticized, the call for an introduction of effective redistributive instruments fed the public concerns on inequality significantly and led to an intensified political debate on reintroducing wealth taxes and increasing inheritance taxation. $^{2}$

\footnotetext{
${ }^{2}$ See, for example, Cnossen and Bovenberg (2001) for the Netherlands, Edson (2012) for Norway,
} 
Most countries levy taxes on specific property, such as real estate, vehicles and other assets. However, many countries have since the 1990s abolished a general wealth taxation (see, for example, OECD 2014). ${ }^{3}$ The following table summarizes information on wealth tax rates and wealth tax abolishment, respectively:

\begin{tabular}{|c|c|c|c|}
\hline Country & Abolition & Tax rate at individual level & Tax rate at corporate level \\
\hline Algeria & & $\max .1 .5 \%$ & \\
\hline Austria & 1994 & & \\
\hline Denmark & 1995 & & \\
\hline Finland & 2006 & & \\
\hline France & & $\max .1 .5 \%$ & \\
\hline Germany & 1997 & & \\
\hline Iceland & & $\max .2 \%$ & \\
\hline India & 2015 & & \\
\hline Ireland & 1997 & & \\
\hline Luxembourg & & & $0.5 \%$ \\
\hline Netherlands & 2001 & & \\
\hline Norway & & $\max .1 .1 \%$ & \\
\hline Spain & 2007, reintroduction 2012 & $\max .2 .5 \%$ & \\
\hline Sweden & 2007 & & \\
\hline Switzerland/Zurich & & $\max .0 .657 \%$ & $0.16425 \%$ \\
\hline
\end{tabular}

Table 1: Wealth taxation and its abolition in selected countries Sources: KPMG (2012a, 2012b), BMF (2013), EY (2014a, 2014b), IBFD (2015)

Notes: Wealth taxes on selected property, like taxes on vehicles, real estate, etc. are not included in this table

The proponents of wealth taxes often link their arguments to the budgetary consequences of the recent financial and fiscal crisis and argue that particularly wealthy people should contribute their fair share to society. Opponents of wealth taxation suspect that wealth taxation could depress investment, hinder or prevent risk-taking and innovations and lead to capital flight. This could induce even lower total tax revenues than in an environment without wealth taxation.

Glennerster (2012) for U.K., Ristea and Trandafir (2010) for Romania, Keuschnigg et al. (2013) for Austria, Sureth and Maiterth (2008), Schratzenstaller (2011), Maiterth and Houben (2012), Spengel, Evers, and Evers (2013), Bach, Beznoska, and Steiner (2014), Hoppe, Maiterth, and Sureth (2015) for Germany. Furthermore, Auerbach and Hassett (2015), who reviewed Piketty's work do not see a wealth tax as an appropriate policy instrument.

${ }^{3}$ High administrative costs, low tax revenues and unsolved problems in asset valuation were the most important causes for abolishing the wealth tax. 
Against the background of this controversial discussion, it is particularly important to disentangle the effects of a wealth tax on investment under uncertainty. In this respect the economic effects crucially depend on the impact of wealth taxes on investment timing, and not only on the decision on whether or not to invest. If risky projects are considered innovative they can significantly contribute to economic growth. Thus, postponement of these projects may be especially harmful for economic development and subsequently for the distribution of income and wealth.

Whereas the effects of profit (or income) taxation under uncertainty are well known since the late 1990s (for example, Niemann 1999a, 1999b, Sureth 1999, Pennings 2000, Agliardi 2001, Panteghini 2001, 2004, 2005, Sureth 2002, Niemann and Sureth 2004, 2005, Alvarez and Koskela 2008, Schneider and Sureth 2010, Gries, Prior, and Sureth 2012, Niemann and Sureth 2013), the effects of wealth taxes have not yet been investigated under conditions of uncertainty and irreversibility. This is surprising against the background of the recent findings on the economic implications of profit taxation on investments in risky projects. Prior literature identified parameter-dependent, partially subsidizing as well as discriminating effects of profit taxation on risky investments that are due to uncertainty (for example, Alvarez and Koskela 2008, Schneider and Sureth 2010, Gries et al. 2012, Niemann and Sureth 2013). These findings indicate that tax reforms that are intended to foster investment such as tax rate cuts, may have dysfunctional effects on investment activities, in particular in high-risk industries. Although wealth taxes are often considered to further hinder risky investment, hardly any corresponding research on wealth taxation under uncertainty has been conducted. If the wealth tax is precisely levied on the market value as defined by the present value of future cash flows from the underlying capital, the investment effects generated by the wealth tax will in present value terms not differ from those of a profit tax. However, for many types of capital assets market values cannot be observed due to a lack of sufficiently liquid markets. Furthermore, the tax legislator for example might intentionally define asset values that are only weakly related to the market 
value to simplify the tax assessment. Consequently, the effects of wealth taxes on risky investments are likely to be different from those of profit taxes. Therefore, a detailed analysis of wealth taxes and their effects on risky investment decisions is important.

Several studies, such as Vlassenko (2001), Arnott (2005), Arnott and Petrova (2006), investigate various property tax systems conceptually and theoretically with respect to efficiency and fairness. Property taxes are similar to wealth taxes as they can be regarded as taxes on specific assets. These studies identify distortions in efficiency of different magnitude depending on the property tax design. Dye, McGuire, and Merriman (2001) study empirically the impact of property taxes on business activities and find that high property tax rates lead to significantly slower growth rates. Craft and Schmidt (2005) find evidence for significant decreases in vehicular capital after changes in vehicle property taxes. In line with that result Allee, Lynch, Petroni, and Schroeder (2015) find significant sensitivities of petroleum refineries in their crude oil inventories when they experience a personal property tax. Hansson (2008) analyzes the abolishment or suspension of general wealth taxation in Austria in 1994, in Denmark in 1997, in Germany in 1997, and in the Netherlands in 2001 empirically using a simple model of the choice between becoming an entrepreneur or an employee. She finds a perceptible but only small impact of wealth tax abolishment on entrepreneurial activity. Obviously, the existing empirical studies do not permit to draw clear-cut conclusions.

In deterministic models the impact of wealth taxes on investment behavior was extensively analyzed in the German analytical tax literature in the 1980s and 1990s, for example, by Wagner/Dirrigl (1980), Siegel (1982), Mellwig (1985), or Georgi (1994). They find that wealth taxation has an ambiguous impact on investment decisions, depending on the valuation of assets for wealth tax purposes.

To the best of our knowledge only van Wijnbergen and Estache (1999) investigate the impact of a special case of wealth taxes under uncertainty explicitly. They examine the 
impact of a minimum asset tax, which is similar to a wealth tax, on high risk firms using an option pricing approach and a Monte Carlo simulation with Brazilian data. They consider uncertain returns and find increased sectorial distortions and that high risk firms do not seem to be hit harder by the underlying tax. Under specific conditions the introduction of the minimum asset tax may even lower the marginal effective tax rates. Their results are in line with the wealth tax paradox that has been elaborated under certainty in Sureth and Maiterth (2008).

Until now, no study has been conducted that addresses the investment and timing effects of a classical wealth tax in a stochastic environment with random cash flows. Particularly, as studies on the recently proposed tax on corporate and individual wealth in Germany indicate severe distortions (Spengel, Evers, and Evers 2013, Hoppe, Maiterth, and Sureth 2015), the investment effects have to be analyzed prior to discussing potential distributional consequences. For example, Hoppe et al. (2015) find in their company data-based simulation that the tax burden on profits is doubled on average and in some cases even quadrupled by the proposed wealth tax. Furthermore, on average $15 \%$ of corporations' equity is lost after six years of wealth taxation implying high risks for firms and jobs. Against the background of these findings, and the partially puzzling results from prior research on wealth taxes, it is important to gain a deeper understanding of the effects of wealth taxes on risky investments. In this respect the economic effects crucially depend on the impact of taxes on investment timing, and not only on the decision on whether or not to invest. If risky projects are considered innovative they can significantly contribute to economic growth. Thus, postponement of these projects may be especially harmful for economic development (Bar-Ilan and Strange 1996, Riddick and Whited 2009, Bachmann, Caballero, and Engel 2013). ${ }^{4}$

To fill the research gap we analyze the impact of wealth taxes on investment timing. We

\footnotetext{
${ }^{4}$ With respect to the impact of uncertainty on postponement of investment see, e.g., Arslan, Atabek, Hulagu, and Şahinöz (2015).
} 
employ a real options model of the Dixit/Pindyck type to model investment behavior under conditions of uncertainty and irreversibility. In addition to a profit tax, a wealth tax is introduced. The wealth tax parameters under consideration include the wealth tax rate, the initial and subsequent valuation of assets for wealth tax purposes, the valuation method (historical cost versus fair value accounting) and the wealth tax treatment of the default alternative. More specifically, our model paves the way for future empirical studies of investment timing under wealth taxation.

This paper is organized as follows. We present our investment model in section 2. The impact of varying wealth tax parameters is analyzed in section 3. Neutrality aspects of wealth taxation are discussed in section 4 . Section 5 summarizes and concludes.

\section{Model setup}

Our model of investment is based on the Dixit/Pindyck framework that is frequently used for the analysis of tax effects under uncertainty and irreversibility. We assume that a riskneutral investor has the option to invest in an infinitely-lived real investment project that yields stochastic cash flows. This option is a proprietary business opportunity, which is due to some earlier business activities by the investor. Typically, the option does not represent an asset that can be recognized or traded. Rather, the option value is a technical construct that is needed for the optimal decision. Since the investor holds a monopoly on the option, we can exclude competition effects. ${ }^{5}$ For reasons of mathematical simplicity the option to invest is considered perpetual. ${ }^{6}$ The investment project can be subject to wealth taxation. The investor uses individual calculus for valuation of both the project and the option to invest. They can either immediately invest into the real investment project or wait until the observable realizations of the cash flows prove to be

\footnotetext{
${ }^{5}$ For strategic option exercise games see, e.g., Grenadier (1996), Grenadier (2002), and Weeds (2002). Grenadier (2002) shows that the impact of competition substantially diminishes the value of the option and induces investment decisions similar to the net present value rule.

${ }^{6}$ Otherwise, the model would involve partial differential equations that cannot be solved analytically.
} 
sufficiently attractive. Thus, the investment problem is two-dimensional as it captures both the decision on whether and when to invest. We do not assume that the so-called spanning property holds, implying that liquid markets for the assets do not necessarily exist. ${ }^{7}$ As long as the option to invest is not exercised available funds yield the riskfree capital market rate. If the option to invest is exercised, the investor gives up all flexibility and pays the deterministic acquisition cost for the project. ${ }^{8}$ We assume that the project is entirely equity-financed to separate the tax effects from investment and financing decisions.

It is the aim of this paper to analyze the combined effects of profit and wealth taxation on investment timing. This research indicates that timing is an important issue in risk-taking decisions and can be interpreted as a measure of an investor's propensity to carry out risky projects. For example, even high-performing firms are continuously challenged by new competitors and new products and services in the market. Thus, firms have to balance out exploitation of their current market share and exploration to generate new innovative products, services and business models. No matter how successful a firm exploits its current portfolio, investments in innovation have to be carried out at some time. As a consequence, the decision on when to shift limited funds from the exploitation strategy to the exploration strategy is an important timing decision. More or less all industries are characterized by this trade-off. Given that real-world investment decisions are typically now-or-later rather than now-or-never decisions, a real option framework is appropriate for analyzing tax effects on investment. Against this background, the tax treatment of the investment project, the option to invest, and the default alternative (wait and see and park funds in a risk-free financial capital market asset) have all to be properly defined.

We consider only one level of taxation and thus abstract from the interaction of corporate

\footnotetext{
${ }^{7}$ As a consequence, a hedge portfolio that is crucial in option pricing theory cannot be built.

${ }^{8}$ Our assumption of deterministic and constant acquisition cost is due to mathematical simplicity. However, it would be possible to model cash flows and acquisition costs as correlated stochastic processes, see Dixit and Pindyck (1994), pp. 207-210. To focus on wealth tax effects we leave this possible extension aside.
} 
and shareholder level taxation. This assumption means that the investor is either a sole proprietor or partner in a partnership (pass-through entity) or a corporation that neglects shareholder taxation in corporate decision making. We do not discuss delegated investment decisions or principal-agent settings. ${ }^{9}$ As long as the investor waits and does not (yet) invest, they earn the nominal risk-free pre-tax interest rate $r$. Interest earned is subject to the tax rate $\tau_{r}$. In accordance with tax law in several countries the tax rate on financial income $\tau_{r} \in\left[0,1\left[\right.\right.$ and the general income tax rate $\tau_{\pi} \in[0,1[$ can differ. ${ }^{10}$ Financial assets like bank accounts or bonds that yield interest income can be (and typically are) subject to wealth taxation at the flat rate $\tau_{\omega} \in[0,1[$. The variable $\gamma \in[0,1]$ denotes the fraction of these financial assets that is subject to wealth taxation. As a result, the discount rate after taxes $r_{\tau}$ is defined as ${ }^{11}$

$$
r_{\tau}=\left(1-\tau_{r}\right) r-\gamma \tau_{\omega}>0
$$

We will relax this assumption later to study how discount rates that are unaffected by taxation, for example, in case of a tax-exempt default investment, affect our finding. Now, we assume that the after-tax discount rate is decreasing in $\tau_{r}$. Furthermore, it is always strictly positive. Otherwise, present values could reach economically meaningless infinite values. $^{12}$

As wealthy investors who tend to have a high savings rate, are likely to invest rather than to consume liquid funds these assumptions about the default alternative are straight-

\footnotetext{
${ }^{9}$ For delegated investment decisions in a real options setting see, e.g., Grenadier/Wang (2005).

${ }^{10}$ In Austria, income from interest, dividends, or capital gains is subject to a flat tax rate of $25 \%$, whereas the personal income tax schedule is progressive with a top marginal tax rate of $50 \%$. In Germany the flat tax on interest and dividend income is $26.375 \%$ (including solidarity surcharge), but the top marginal tax rate of the personal income tax is $47.475 \%$. By contrast, Croatia is one of the few countries which until 2014 did not tax individual interest income. Overall, many European and Asian countries are characterized by tax systems with different tax scales on interest and dividend income on the one hand side and other income (business, labor, etc.) on the other hand side. By contrast, the tax systems in the Americas are typically characterized by a uniform tax rate on all types of income.

${ }^{11}$ With respect to the effect of a wealth tax rate on the rate of interest see, e.g., Atkinson (1971, p. 217).

${ }^{12}$ Although an allowance for corporate equity (ACE) tax could be interpreted as a negative wealth tax, we do not consider an ACE tax in our model. Due to the close connection of ACE and income taxation, integrating an ACE would conceal rather than explain the wealth tax effects.
} 
forward. Moreover, under some standard capital market assumptions, investment and consumption decisions are separable. ${ }^{13}$ In this case, the investor's time preference rate would coincide with the capital market rate and it would not be necessary to take consumption explicitly into account.

If however, the capital market properties did not permit this separation, the investor had to decide between investment and consumption. This situation could be modelled by an individual time preference rate $\psi$ that would be used for discounting instead of the risk-free interest rate $r$. As an exogenous parameter that reflects the investor's individual preferences, $\psi$ would be unaffected by taxes: $\partial \psi / \partial \tau_{r}=\partial \psi / \partial \tau_{\omega}=\partial \psi / \partial \gamma=0$. The resulting wealth tax effects therefore would be identical to the case with a constant risk-free interest rate that is unaffected by (wealth) taxes: $\gamma=\partial r_{\tau} / \partial \tau_{\omega}=0$. Consequently, this special case not only corresponds to a wealth tax-exempt default alternative, but also reflects an explicit comparison of investment and consumption. To consider these important special cases, the parameter setting $\gamma=0$ is constantly addressed in the subsequent analysis.

If the investor decides to exercise the option to invest and to acquire the investment project, they lose any further timing flexibility and are bound to the project until infinity. However, the model does not include an obligation to invest in finite time. If the project conditions are not sufficiently favorable the investor could theoretically postpone it until infinity. We normalize the acquisition cost to unity $\left(I_{0}=1\right)$. Once the project is in place its only benefits consist of the future operating cash flows $\pi$. Thus, the pre-tax value of the investment project is simply its expected present value.

In the following we develop our model stepwise, beginning with the pre-tax case (Dixit and Pindyck 1994, pp. 138-140, Gries et al. 2012, p. 522). First, we abstract from uncertainty and growth. Then, we integrate growth, taxes and uncertainty. Under certainty and

\footnotetext{
${ }^{13}$ See Fisher (1930, pp. 129-141) and Hirshleifer (1958).
} 
constant pre-tax cash flows $\pi(t)=\pi$ the option value is equal to zero and the pre-tax present value $V$ of the project at time $t=0$ computed with the pre-tax interest rate $r$ is

$$
V^{\text {certainty }}=\int_{0}^{\infty} \pi e^{-r \cdot t} d t=\frac{\pi}{r}
$$

which is independent of $t$. The optimal time to invest is given by the critical thresholds

$$
V^{* \text { certainty }}=\frac{\pi}{r} \quad \Rightarrow \quad \pi^{* \text { certainty }}=r
$$

Whenever $\pi>r$ the investment should be carried out immediately. Otherwise, investment should never be carried out. If the pre-tax cash flows $\pi(t)$ grow deterministically at the constant rate $\alpha$, with $\alpha<r$, we obtain $\pi(t)=\pi(0) \cdot e^{\alpha t}$ and the present value of the project is

$$
V^{\text {certainty }}=\int_{0}^{\infty} \pi(t) e^{-r \cdot t} d t=\frac{\pi(0)}{r-\alpha}
$$

so that the critical threshold of the initial cash flow is given by

$$
\pi^{*} \text { certainty }=r-\alpha .
$$

Introducing timing flexibility, the project value can be written as

$$
V^{\text {certainty,growth }}(s)=\int_{s}^{\infty} \pi(0) e^{-(r-\alpha)(t-s)} d t=\frac{\pi(0) \cdot e^{\alpha s}}{r-\alpha} .
$$

Although this is a present value under certainty the positive growth parameter $\alpha$ implies that the opportunity to invest at some future time $s$ has a positive economic value that can be interpreted as an option value F (Dixit and Pindyck 1994, pp. 138-139) with ${ }^{14}$

$$
F=\max _{s}\left[\frac{\pi(0) \cdot e^{\alpha s}}{r-\alpha}-1\right] \cdot e^{-r s} .
$$

Maximizing $F$ with respect to $s$ yields the optimal investment time

$$
\begin{aligned}
\frac{d F}{d s} & =-\pi(0) \cdot e^{-(r-\alpha) s}+r \cdot e^{-r s}=0 \\
\Rightarrow \quad s^{*} & =\max \left\{0, \frac{1}{\alpha} \ln \left[\frac{r}{\pi(0)}\right]\right\} .
\end{aligned}
$$

\footnotetext{
${ }^{14}$ For $\alpha \leq 0, F(V)$ is decreasing in $s$ so that immediate investment would be optimal if $V(0)>1$. In this case the option value would be given by $F(V)=\max \{V-1,0\}$.
} 
Now, immediate investment $\left(s^{*}=0\right)$ would be optimal for

$$
\frac{r}{\pi(0)} \leq 1 \quad \Leftrightarrow \quad \pi(0) \geq r
$$

In the case of immediate investment with the critical threshold $\pi(0)=r$, the project value is

$$
\left.V\right|_{s^{*}=0} ^{\text {certainty,growth }}=\frac{r}{r-\alpha}>1=I_{0}
$$

implying a strictly positive NPV of the project. Substituting (9) in (7) yields the value of the option to invest

$$
F=\left\{\begin{array}{cc}
\frac{\alpha}{r-\alpha}\left(\frac{\pi_{0}}{r}\right)^{\frac{r}{\alpha}} & \text { for } \pi \leq \pi^{*}, \\
V-1 & \text { otherwise. }
\end{array}\right.
$$

The after-tax case can be derived similarly. The operating cash flows $\pi$ are subject to income taxation. Operating cash flows as well as interest rates are given in nominal terms, which means that they are not adjusted for inflation. Depreciation $d_{\pi}(t)$ can be deducted from the tax base. Since depreciation deductions are generally not proportional to pre-tax cash flows, after-tax cash flows do not grow at a constant rate even if pre-tax cash flows do. Therefore, the resulting formulae are more complicated than those shown for the pretax case. For analytical simplicity we assume that depreciation deductions for income tax purposes are based on the acquisition cost of the project and decrease exponentially at the rate $\delta_{\pi} \cdot{ }^{15}$ Thus, depending on the time structure of the project's cash flow depreciation allowances may deviate from a neutral scheme of an economic depreciation. For an initial outlay normalized to unity $\left(I_{0}=1\right)$ the depreciation deduction for income tax purposes at time $t$ is

$$
d_{\pi}(t)=\delta_{\pi} e^{-\delta_{\pi} t}
$$

Assuming a full and complete loss-offset, the cash flow after income taxes at time $t$ amounts to

$$
\pi(t)-\tau_{\pi}\left[\pi(t)-d_{\pi}(t)\right]=\left(1-\tau_{\pi}\right) \pi(t)+\tau_{\pi} \delta_{\pi} e^{-\delta_{\pi} t}
$$

\footnotetext{
${ }^{15}$ This assumption does not restrict generality, because any other depreciation schedule like straightline depreciation or double-declining balance depreciation can be transformed to exponential depreciation in identical present value terms. A similar approach is used in analytical models of effective tax rates, e.g., by King and Fullerton (1984, p. 29).
} 
The wealth tax has to be subtracted as second tax term from this (preliminary) cash flow. If the wealth tax base at time $t$ is given by $W(t)$, total cash flow after taxes is

$$
\pi_{\tau}(t)=\left(1-\tau_{\pi}\right) \pi(t)+\tau_{\pi} \delta_{\pi} e^{-\delta_{\pi} t}-\tau_{\omega} W(t)
$$

The investor wants to determine the optimal time to invest and thus maximizes their current wealth

$$
\max \left\{V_{\tau}-1, F_{\tau}\right\}
$$

This implies that the investor exercises the option to invest if the expected after-tax net present value of the real investment project reaches the value of the option $F_{\tau}$.

We will now proceed with the after-tax case under growth and uncertainty. Assuming stochastic cash flows $\pi_{\tau}(t)$ and a risk neutral investor the after-tax value of the project in place $V_{\tau}$ at time $t=0$ is defined as the expected net present value

$$
V_{\tau}=V_{\tau}(0)=E\left[\int_{0}^{\infty} \pi_{\tau}(t) e^{-r_{\tau} t} d t\right] .
$$

For further results the cash flow process has to be defined. In accordance with prior literature (for example, McDonald and Siegel 1985, Dixit and Pindyck 1994, Niemann 1999b, Sureth 2002, Niemann and Sureth 2004, 2005) we assume that the pre-tax cash flow $\pi$ follows a geometric Brownian motion

$$
\frac{d \pi}{\pi}=\alpha d t+\sigma d z
$$

with $\alpha<r_{\tau}$ as the expected growth rate of cash flows, $\sigma$ as the volatility rate, and $d z$ as increment of a standard Wiener process. Consequently, the expected pre-tax cash flow at time $t$ after investment is

$$
E[\pi(t)]=\pi(0) e^{\alpha t}=\pi_{0} e^{\alpha t},
$$

which permits to write the project value as

$$
\begin{aligned}
V_{\tau} & =E\left[\int_{0}^{\infty}\left[\left(1-\tau_{\pi}\right) \pi(t)+\tau_{\pi} \delta_{\pi} e^{-\delta_{\pi} t}-\tau_{\omega} W(t)\right] e^{-r_{\tau} t} d t\right] \\
& =\frac{\left(1-\tau_{\pi}\right) \pi_{0}}{r_{\tau}-\alpha}+\frac{\tau_{\pi} \delta_{\pi}}{\delta_{\pi}+r_{\tau}}-\tau_{\omega} E\left[\int_{0}^{\infty} W(t) e^{-r_{\tau} t} d t\right]
\end{aligned}
$$


Thus, the project value is defined as the sum of the present values of cash flows after income taxes and tax savings due to depreciation deductions, less the present value of wealth tax payments.

With regard to the wealth tax base we have to distinguish two general concepts: fair value accounting and historical cost accounting. ${ }^{16}$ Under historical cost accounting for tax purposes the initial wealth tax base $W(0)$ equals some predefined constant: $W(0)=\bar{W}$. The acquisition cost $\bar{W}_{H C}=I_{0}=1$ is the most important special case for the initial value. However, it is also possible - and current tax practice for assets in some jurisdictions that the initial value of an asset for wealth tax purposes does not relate to acquisition cost or market price. ${ }^{17}$

Subsequent valuation under historical cost accounting is a function of the initial value $\bar{W}$. Similar to the valuation for income tax purposes we assume that the value for wealth tax purposes is written off exponentially at the rate $\delta_{\omega}: W_{H C}(t)=\bar{W}_{H C} \cdot e^{-\delta_{\omega} t} \cdot{ }^{18}$ The depreciation parameter $\delta_{\omega}$ is not necessarily positive, so that increasing or constant values are also possible. To avoid infinite present values we only require that $\delta_{\omega}>-r_{\tau}$ holds. Under these assumptions the total project value simplifies to

$$
V_{H C}=\frac{\left(1-\tau_{\pi}\right) \pi_{0}}{r_{\tau}-\alpha}+\frac{\tau_{\pi} \delta_{\pi}}{r_{\tau}+\delta_{\pi}}-\frac{\tau_{\omega} \bar{W}_{H C}}{r_{\tau}+\delta_{\omega}}
$$

Under fair value accounting the initial wealth tax base should refer to the present value of the project at time $t=0$. Since market values do not necessarily exist for each asset, it

\footnotetext{
${ }^{16}$ Whenever we use the terms "fair value accounting" or "historical cost accounting", we refer to accounting for tax purposes rather than financial accounting. Financial accounting is not considered in this paper. Prior literature on property taxation indicates that the valuation method is crucial for the investment effects of non-profit taxes. See, e.g., Bentick (1979), Arnott (2005), Arnott and Petrova (2006).

${ }^{17}$ The real estate tax (Grundsteuer) in Austria and in Germany can serve as an example for a rather arbitrary valuation, because the assessed tax value (Einheitswert) is neither based on acquisition cost nor on market value. The Austrian Constitutional Court even decreed the abolishment of the Austrian estate tax due to the (extremely) unequal valuation of real estate compared to other assets. See Verfassungsgerichtshof Österreich (2007).

${ }^{18}$ Again, any other depreciation schedule can be replicated by exponential depreciation in present value terms. Hence, the assumption of exponential depreciation does not restrict generality.
} 
is common practice for the fiscal authorities to use multiplier methods based on current cash flows or even past cash flows from annual financial statements to approximate market values (for example, Müller and Sureth 2011, Müller 2014). ${ }^{19}$ We assume that the fiscal authorities use a multiplier $f(\rho)=1 / \rho>0$ for wealth tax purposes to compute the project's initial value

$$
\bar{W}_{F V}=\frac{\pi_{0}}{\rho} .
$$

This assumption implies that the growth and discount rates of the investor and the tax authorities do not necessarily coincide, $\rho \gtreqless\left(r_{\tau}-\alpha\right)$. Like under historical cost accounting the subsequent value for wealth tax purposes is written off exponentially at the rate $\delta_{\omega}$ : $W_{F V}(t)=\bar{W}_{F V} \cdot e^{-\delta_{\omega} t}$. Again, $\delta_{\omega}$ can be positive, zero, or negative as long as the condition $\delta_{\omega}>-r_{\tau}$ holds. Consequently, the project value under fair value accounting is given by

$$
V_{F V}=\frac{\left(1-\tau_{\pi}\right) \pi_{0}}{r_{\tau}-\alpha}+\frac{\tau_{\pi} \delta_{\pi}}{r_{\tau}+\delta_{\pi}}-\tau_{\omega} \frac{\frac{\pi_{0}}{\rho}}{r_{\tau}+\delta_{\omega}} .
$$

In contrast to historical cost accounting, the current value of the cash flow $\pi_{0}$ affects the present value of expected wealth tax payments in the third summand. ${ }^{20}$

Given the value of the investment project we can determine the value of the option to invest. Since the investor can only decide between waiting or exercising the option, the decision variable is binary, and it is easily possible to determine the optimal investment behavior. We will start with the waiting region in which the option is kept alive. The optimal transition to the exercise region will be modeled by boundary conditions. Under the given set of assumptions with a perpetual option to wait and stochastic cash flows that grow at the expected rate $\alpha$, the originally two-dimensional investment problem of whether and when to invest collapses to a pure timing problem. Consequently, there exists an optimal one-dimensional threshold for transition. To solve this problem we use

\footnotetext{
${ }^{19}$ For valuation techniques using multiples see Damodaran (2011).

${ }^{20}$ We abstract from implications of a possible impact of the valuation approach on the volatility of the market value as indicated, e.g., by Laux and Leuz (2009, 2010) and Laux (2012).
} 
dynamic programming to determine the option value. ${ }^{21}$

The option to invest itself does not generate any cash flows and thus no income tax base. In principle, an option could be relevant for income tax as well as wealth tax purposes. For example, the increase or decrease of the option value could be taxable or tax-deductible under a given income tax scheme, respectively. ${ }^{22}$ Alternatively, the option value could be subject to wealth taxation. However, tax systems in the real world do not recognize mere business opportunities as taxable assets. Therefore, we neglect tax consequences of the option to invest that might be relevant in ideal tax systems. Thus, the option's after-tax cash flow equals zero in the case considered here.

As long as the option is kept alive, its only benefit is the expected increase in value. The resulting equilibrium condition implies that the owner of the option expects an instantaneous return that equals the after-tax risk-free rate:

$$
E\left[d F_{\tau}\right] \stackrel{!}{=} r_{\tau} d t
$$

Application of Itô's lemma to the stochastic differential $d F_{\tau}$ and further transformation yields the ordinary differential equation ${ }^{23}$

$$
\frac{1}{2} \sigma^{2} \pi^{2} \frac{d^{2} F_{\tau}}{d \pi^{2}}+\alpha \pi \frac{d F_{\tau}}{d \pi}-r_{\tau} d t=0
$$

with the solution

$$
F_{\tau}(\pi)=A \pi^{\beta_{\tau}}, \quad \text { with } \beta_{\tau}=\frac{1}{2}-\frac{\alpha}{\sigma^{2}}+\sqrt{\left(\frac{1}{2}-\frac{\alpha}{\sigma^{2}}\right)^{2}+\frac{2 r_{\tau}}{\sigma^{2}}}>1,
$$

where $A>0$ is a constant to be determined. From $A, \beta_{\tau}>0$ it is obvious that $F_{\tau}(0)=0$ holds. This condition implies that an option on a valueless underlying is itself valueless. ${ }^{24}$

\footnotetext{
${ }^{21}$ For a comparison of dynamic programming and contingent claims analysis and the resulting tax effects see Niemann and Sureth (2004, 2005).

${ }^{22}$ Acquired real options like exploration rights, e.g., are depreciable under most tax regimes. Depreciation deductions on the option to invest are necessary in some neutral tax systems. See Niemann (1999b, pp. 57,61).

${ }^{23}$ Since the option to invest is perpetual, the time derivative vanishes here.

${ }^{24}$ Deriving the social value of the option would require extensive information that is beyond the scope of this model, such as social preferences or a social discount rate. Thus, we focus on the individual perspective. Musumeci and Sansing (2014) refer to the social value as an aggregate of project value and the present value of profit taxes collected by the government.
} 
To derive the solution of the investment problem - the critical investment threshold at which it is optimal to exercise the option immediately - two free boundary conditions are needed (Dixit and Pindyck 1994, p. 141). The value matching condition requires that the project's benefits, as defined by its expected present value, must equal its costs, given by acquisition costs and abandoned option value, at the point of transition.

$$
V_{\tau}\left(\pi_{0}\right)-1 \stackrel{!}{=} F_{\tau}\left(\pi_{0}\right)
$$

The smooth pasting condition requires the identity of marginal benefits and marginal costs at the critical threshold.

$$
\frac{d V_{\tau}\left(\pi_{0}\right)}{d \pi_{0}} \stackrel{!}{=} \frac{d F_{\tau}\left(\pi_{0}\right)}{d \pi_{0}}
$$

Since the project value depends on whether historical cost accounting or fair value accounting is used for wealth tax purposes, we have to compute two different critical thresholds from the value matching and the smooth pasting conditions.

The critical threshold for historical cost valuation is given by ${ }^{25}$

$$
\pi_{0}^{H C}=\frac{\beta_{\tau}}{\beta_{\tau}-1} \cdot \frac{r_{\tau}-\alpha}{1-\tau_{\pi}}\left(1-\tau_{\pi} D_{\pi}+\tau_{\omega} D_{\omega}\right), \quad \text { with } D_{\pi}=\frac{\delta_{\pi}}{r_{\tau}+\delta_{\pi}}, \quad D_{\omega}=\frac{\bar{W}_{H C}}{r_{\tau}+\delta_{\omega}}
$$

or, equivalently

$$
\underbrace{\frac{1-\tau_{\pi}}{r_{\tau}-\alpha} \cdot \pi_{0}^{H C}}_{\text {after-tax PV of cash flows }}=\underbrace{\frac{\beta_{\tau}}{\beta_{\tau}-1}}_{>1}(\underbrace{1}_{\text {acquisition costs }}-\underbrace{\tau_{\pi}^{D_{\pi}}}_{\begin{array}{c}
\text { PV of tax savings from } \\
\text { depreciation deductions }
\end{array}}+\underbrace{\tau_{\omega} D_{\omega}}_{\text {PV of wealth tax }}) .
$$

Equation (30) can be interpreted as follows. The expected present value of after-tax cash flows must exceed the effective acquisition cost of a project by a multiple $\beta_{\tau} /\left(\beta_{\tau}-1\right)>1$ to cover the value of the option which is lost due to exercise. The effective acquisition cost comprise the gross acquisition cost $I_{0}=1$ less the present value of the tax shield of depreciation deductions for income tax purposes $\tau_{\pi} D_{\pi}$ plus present value of wealth

\footnotetext{
${ }^{25}$ The function $\pi_{0}$ (without superscript) denotes a pre-tax function or pre-tax threshold. By contrast, superscripts $H C$ or $F V$ indicate after-tax functions or after-tax thresholds.
} 
taxes $\tau_{\omega} D_{\omega}$ to be paid during the infinite lifetime of the project. For $\tau_{\omega}=0$ the critical threshold $\pi_{0}^{H C}$ from (29) is identical to the thresholds developed in the earlier literature with income taxes only. ${ }^{26}$

Under fair value accounting for wealth tax purposes with initial value $\bar{W}_{F V}=\pi_{0} / \rho$ the critical threshold is different from (29), because the critical value $\pi_{0}$ appears twice in the project value (23).

$$
\pi_{0}^{F V}=\frac{\beta_{\tau}}{\beta_{\tau}-1} \cdot \frac{\rho\left(r_{\tau}-\alpha\right)\left(r_{\tau}+\delta_{\omega}\right)}{\rho\left(1-\tau_{\pi}\right)\left(r_{\tau}+\delta_{\omega}\right)-\tau_{\omega}\left(r_{\tau}-\alpha\right)}\left(1-\tau_{\pi} D_{\pi}\right) .
$$

Since the critical investment thresholds (29) and (31) are finite, they are reached within finite time in expected value terms, given the assumption of a geometric Brownian motion. From a tax politician's perspective it might be relevant whether this expected time is within the current legislation cycle.

To isolate the uncertainty effect, we can derive the pre-tax investment threshold under uncertainty as a special case from (29) and (31) by setting all tax rates to zero: $\tau_{r}=$ $\tau_{\pi}=\tau_{\omega}=0 .{ }^{27}$

$$
\begin{aligned}
\pi_{0}^{*}= & \left.\pi_{0}^{H C}\right|_{\tau_{r}=\tau_{\pi}=\tau_{\omega}=0}=\left.\pi_{0}^{F V}\right|_{\tau_{r}=\tau_{\pi}=\tau_{\omega}=0}=\frac{\beta}{\beta-1}(r-\alpha) \\
& \text { with } \beta=\left.\beta_{\tau}\right|_{\tau_{r}=\gamma=0}=\frac{1}{2}-\frac{\alpha}{\sigma^{2}}+\sqrt{\left(\frac{1}{2}-\frac{\alpha}{\sigma^{2}}\right)^{2}+\frac{2 r}{\sigma^{2}}} \geq \beta_{\tau}>1 .
\end{aligned}
$$

Obviously, the uncertainty effect is reflected in the fraction $\beta /(\beta-1)>1$. This implies that the expected NPV of the project is strictly positive at the time of exercise:

$$
V=V(0)=E\left[\int_{0}^{\infty} \pi_{0}^{*} e^{-r t} d t\right]=\frac{\beta}{\beta-1}>1
$$

Under certainty $\left(\sigma^{2}=0\right)$, however, we have

$$
\lim _{\sigma \rightarrow 0} \frac{\beta}{\beta-1}=1,
$$

\footnotetext{
${ }^{26}$ See, for example, Niemann and Sureth 2005, p. 82.

${ }^{27}$ See Dixit and Pindyck 1994, p. 143. In case of non-separability of investment and consumption, the interest rate $r$ should be replaced by the time preference rate $\psi$.
} 
implying a critical investment threshold $\pi_{0}^{*}=r-\alpha$, which is equivalent to the deterministic case without timing flexibility, eq. (5).

\section{Investment timing effects of wealth taxation}

The impact of wealth taxation on investment timing can be determined by computing the partial derivatives of the critical investment threshold $\pi_{0}^{H C} / \pi_{0}^{F V}$ with respect to the different wealth tax parameters. These parameters are:

- initial tax value of the project $\bar{W}_{H C}$ for historical cost accounting,

- multiplier $1 / \rho$ for the initial tax value under fair value accounting,

- valuation method (historical cost versus fair value accounting),

- depreciation rate for wealth tax purposes $\delta_{\omega}$,

- taxable fraction of financial assets $\gamma$ (wealth taxation of the default alternative), ${ }^{28}$

- wealth tax rate $\tau_{\omega}$.

Proposition 1 Increasing the initial tax value of the project $\bar{W}_{H C}$ under historical cost accounting unambiguously increases the critical investment threshold. ${ }^{29}$

Proof.

$$
\frac{\partial \pi_{0}^{H C}}{\partial \bar{W}_{H C}}=\frac{\beta_{\tau}}{\beta_{\tau}-1} \cdot \frac{r_{\tau}-\alpha}{1-\tau_{\pi}} \cdot \frac{\tau_{\omega}}{r_{\tau}+\delta_{\omega}}>0
$$

Proposition 2 Increasing the multiplier $f(\rho)=1 / \rho$ under fair value accounting unambiguously increases the critical investment threshold.

\footnotetext{
${ }^{28}$ E.g., in case of a property tax on real estate or a vehicle property tax we assume $\gamma=0$. Usually, a general wealth tax implies $\gamma=1$.

${ }^{29}$ This partial derivative only makes sense under historical cost accounting. Under fair value accounting, the initial tax value $\bar{W}_{F V}$ is a function of the cash flow $\pi_{0}$.
} 


\section{Proof.}

$$
\begin{aligned}
\frac{\partial \pi_{0}^{F V}}{\partial \rho} & =-\frac{\beta_{\tau}}{\beta_{\tau}-1} \cdot \frac{\tau_{\omega}\left(r_{\tau}-\alpha\right)^{2}\left(r_{\tau}+\delta_{\omega}\right)}{\left[\rho\left(1-\tau_{\pi}\right)\left(r_{\tau}+\delta_{\omega}\right)-\tau_{\omega}\left(r_{\tau}-\alpha\right)\right]^{2}}\left(1-\frac{\tau_{\pi} \delta_{\pi}}{r_{\tau}+\delta_{\pi}}\right)<0 . \\
\text { Because } \frac{\partial f}{\partial \rho} & =-\frac{1}{\rho^{2}}<0 \text { and } \\
\frac{\partial \pi_{0}^{F V}}{\partial \rho} & =\frac{\partial \pi_{0}^{F V}}{\partial f} \cdot \frac{\partial f}{\partial \rho} \\
\Leftrightarrow \quad \frac{\partial \pi_{0}^{F V}}{\partial f} & =\frac{\frac{\partial \pi_{0}^{F V}}{\partial \rho}}{\frac{\partial f}{\partial \rho}}>0 .
\end{aligned}
$$

The economic reasoning for both results is as follows. The higher the initial tax value of the project, the higher the present value of wealth tax payments, whereas both the default alternative and the value of the option to invest remain unchanged. Consequently, higher initial tax values lead to lower expected after-tax returns from the risky investment, require higher future cash flows and thus increase investment thresholds. As a result, investment is delayed. Identical results hold under certainty $\left(\sigma^{2}=0\right)$, because varying $\sigma^{2}$ does not alter the algebraic sign of $\beta_{\tau} /\left(\beta_{\tau}-1\right)$.

We can observe a corresponding result if we vary the subsequent valuation of the project, which we model using the depreciation rate for wealth tax purposes $\delta_{\omega}$.

Proposition 3 Increasing the depreciation rate for wealth tax purposes $\delta_{\omega}$ under historical cost accounting and fair value accounting unambiguously reduces the critical investment threshold.

\section{Proof.}

$$
\begin{aligned}
\frac{\partial \pi_{0}^{H C}}{\partial \delta_{\omega}} & =-\frac{\beta_{\tau}}{\beta_{\tau}-1} \cdot \frac{r_{\tau}-\alpha}{1-\tau_{\pi}} \cdot \frac{\tau_{\omega} \bar{W}_{H C}}{\left(r_{\tau}+\delta_{\omega}\right)^{2}}<0 \\
\frac{\partial \pi_{0}^{F V}}{\partial \delta_{\omega}} & =-\frac{\beta_{\tau}}{\beta_{\tau}-1} \cdot \frac{\rho \tau_{\omega}\left(r_{\tau}-\alpha\right)^{2}}{\left[\rho\left(1-\tau_{\pi}\right)\left(r_{\tau}+\delta_{\omega}\right)-\tau_{\omega}\left(r_{\tau}-\alpha\right)\right]^{2}} \cdot\left(1-\frac{\tau_{\pi} \delta_{\pi}}{r_{\tau}+\delta_{\pi}}\right)<0 .
\end{aligned}
$$


Higher depreciation deductions for wealth tax purposes reduce the present value of wealth tax payments of the project. Again, both the default alternative and the value of the option to invest remain unchanged. As a consequence, investment is accelerated, which is also true under certainty.

In contrast to the previous results, the choice of the valuation method by the tax legislator induces ambiguous effects on investment timing. Whether historical cost valuation or fair value accounting are more likely to accelerate or delay investments depends on the initial value $\bar{W}_{H C}$ and the multiplier $1 / \rho$.

Proposition 4 The critical thresholds under historical cost valuation or fair value accounting are identical only if the following relation of $\bar{W}_{H C}$ and $\rho$ holds: ${ }^{30}$

$$
\pi_{0}^{H C}=\pi_{0}^{F V} \Leftrightarrow \quad \bar{W}_{\overparen{H C}}=\frac{r_{\tau}+\left(1-\tau_{\pi}\right) \delta_{\pi}}{r_{\tau}+\delta_{\pi}} \cdot \frac{\left(r_{\tau}+\delta_{\omega}^{H C}\right)\left(r_{\tau}-\alpha\right)}{\rho\left(1-\tau_{\pi}\right)\left(r_{\tau}+\delta_{\omega}^{F V}\right)-\tau_{\omega}\left(r_{\tau}-\alpha\right)} .
$$

For $\bar{W}_{H C}=\bar{W}_{\widetilde{H C}}$ the investor is indifferent between both valuation methods. For $\bar{W}_{H C}>$ $(<) \bar{W}_{\widetilde{H C}}$ historical cost valuation would delay (accelerate) investment compared to fair value accounting.

Corollary 1 The effects of varying the taxable fraction of financial assets $\gamma$ are ambiguous.

Corollary 2 The effects of varying the wealth tax rate $\tau_{\omega}$ are ambiguous.

Proof. To prove the existence of ambiguous results it is sufficient to show that the partial derivatives $\partial \pi_{0}^{H C / F V} / \partial \gamma$ and $\partial \pi_{0}^{H C / F V} / \partial \tau_{\omega}$ may take either algebraic sign for at least one parameter setting. See the numerical results below.

The effects of varying the taxable fraction of financial assets $\gamma$ and the wealth tax rate $\tau_{\omega}$ depend on the tax and non-tax parameters $r, \alpha, \sigma, \tau_{r}, \tau_{\pi}, \tau_{\omega}$, and $\gamma$. Although the

\footnotetext{
${ }^{30}$ The indifference condition accounts for different depreciation deductions for historical cost and fair value accounting. The respective values for $\delta_{\omega}$ are indicated with superscripts $H C$ and $F V$.
} 
partial derivatives $\partial \pi_{0}^{H C / F V} / \partial \gamma$ and $\partial \pi_{0}^{H C / F V} / \partial \tau_{\omega}$ are too complicated to be studied analytically, numerical examples show that either algebraic sign is possible. In line with prior reasoning on the wealth tax effects on investment decisions under certainty (Wagner and Dirrigl 1980, Siegel 1982, Mellwig 1985 and Georgi 1994) we find puzzling and probably unintended effects of wealth taxation under uncertainty. In the following, we elaborate on which effect prevails under specific conditions. We define the effects of wealth taxation as "normal" if increasing wealth taxation of the investment project increases the critical investment threshold and thus delays investment and if increasing wealth taxation of financial assets (default alternative) reduces the critical investment threshold, i.e. if $\partial \pi_{0}^{H C / F V} / \partial \tau_{\omega}>0$ or $\partial \pi_{0}^{H C / F V} / \partial \gamma<0$. Otherwise, for $\partial \pi_{0}^{H C / F V} / \partial \tau_{\omega}<0$ or $\partial \pi_{0}^{H C / F V} / \partial \gamma>0$, we call the emerging tax effects "paradoxical". ${ }^{31}$ Further computations of the partial derivatives $\partial \pi_{0}^{H C} / \partial \tau_{\omega}$ and $\partial \pi_{0}^{H C} / \partial \gamma$ in the limiting cases $\sigma \rightarrow 0$ (certainty), $\sigma \rightarrow \infty, r \rightarrow \infty$ are included in the appendix.

With respect to $\gamma$, the occurrence of normal or paradoxical wealth tax effects essentially depends on the level of the after-tax discount rate. For sufficiently high after-tax discount rates $r_{\tau}$, normal tax effects prevail. Hence, for high pre-tax interest rates, real-world levels of income tax rates $\tau_{\pi}$ and $\tau_{r}$, and low or moderate levels of the wealth tax rate $\tau_{\omega}$, the partial derivatives $\partial \pi_{0}^{H C} / \partial \gamma$ and $\partial \pi_{0}^{F V} / \partial \gamma$ are negative, which means that increasing the taxable fraction of financial assets reduces the critical investment threshold and hence accelerates real investment. This effect is plausible, because increasing $\gamma$ does not affect cash flows from investment and only reduces the after-tax discount rate $r_{\tau}$. Hence, the real investment benefits in relative terms from the higher wealth taxation of the default alternative. Therefore, the present value of the investment project increases while the corresponding increase of the present value of wealth tax payments is not equally substantial. Moreover, a lower discount rate typically reduces option values (for example, Merton 1973), which makes immediate investment more attractive. An increased project

\footnotetext{
${ }^{31}$ For paradoxical income tax effects see, e.g., Niemann and Sureth (2013). For the wealth tax paradox see Sureth and Maiterth (2008).
} 
value and a reduced option value both contribute to accelerated investment.

However, with after-tax discount rates sufficiently close to zero, increasing $\gamma$ increases the critical investment threshold so that a paradoxical wealth tax effect occurs. ${ }^{32}$ In these cases, increasing $\gamma$ reduces the discount rate such that the present value of wealth taxes increases relatively more than the present value of cash flows. This paradoxical effect can be shown under historical cost valuation as well as under fair value accounting. The wealth tax paradox occurs for low pre-tax interest rates and a high level of the wealth tax rate. Hence, as investors currently face very low interest rates in the capital market, paradoxical effects are likely to occur. These effects tend to be even more distinctive for high cash flow uncertainty. The identified effects are highly relevant and should be considered by investors and politicians.

Similar to the decision under certainty, depreciation of the project for wealth tax purposes is a crucial determinant of paradoxical tax effects. If the investment project is depreciated sufficiently quickly, increased wealth taxation is likely to accelerate investment. In addition to the decision under certainty, the value of the option to invest has to be considered. If the option is disregarded for tax purposes and hence not subject to wealth taxation (despite its positive economic value), it has a relative benefit compared to the pre-tax case. The resulting relative increase of the option value tends to delay investment, hereby mitigating paradoxical wealth tax effects.

To illustrate scenarios that lead to normal and paradoxical wealth tax effects we use numerical examples with the parameters $r=0.04, \alpha=0, \sigma=0.3, \tau_{\pi}=\tau_{r}=0.25, \delta_{\pi}=$ 0.3 (Figure 1). ${ }^{33}$

\footnotetext{
${ }^{32}$ See Gries et al. (2012), who identify general conditions for neutral, normal, and paradoxical tax regimes if the differential between the drift parameter of the stochastic cash flow and the after-tax interest rate is sufficiently small.

${ }^{33}$ The after-tax discount rate $r_{\tau}$ is always strictly positive in the examples considered here.
} 
For $\delta_{\omega}=0$ the wealth tax value of the investment project is constant over time. Examples for a time-invariant tax value are investments in land or corporate stock. ${ }^{34}$ Figure 1 displays the critical investment threshold under historical cost accounting as a function of the parameter $\gamma$. Currently, wealth tax rates range from $0.5 \%$ to $2.5 \%$ (see Table 1 ). We observe normal effects with respect to $\gamma$ for $\tau_{\omega}=0.01$ (dashed line, slightly decreasing), and paradoxical effects for $\tau_{\omega}=0.02$ (dotted line, increasing). As a reference case, the solid line indicates the critical threshold without wealth taxation $\left(\tau_{\omega}=0\right)$. For fair value accounting, the effects are similar and therefore not displayed here.

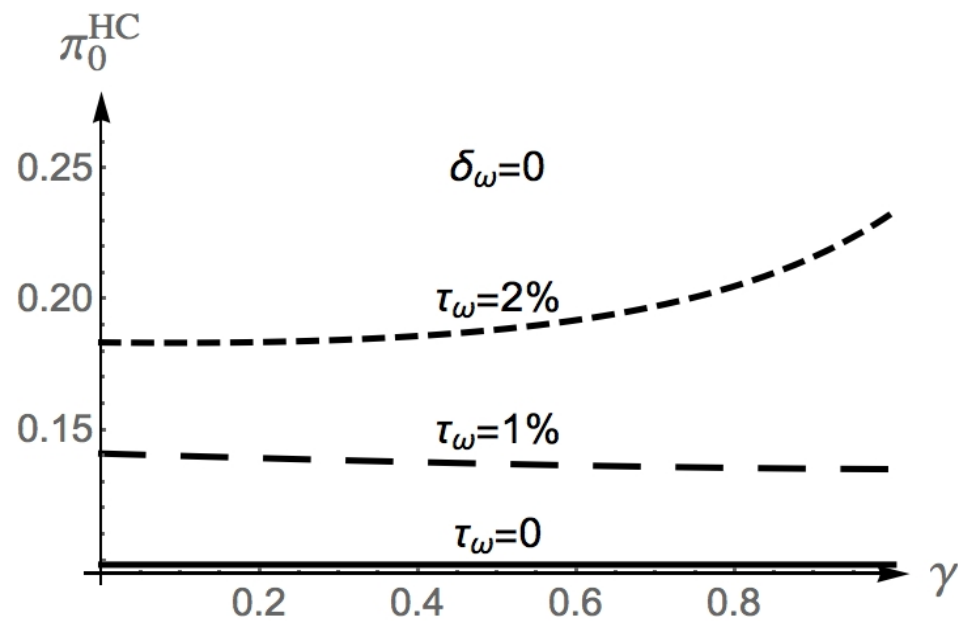

Figure 1: Critical investment threshold under historical cost accounting as a function of the wealth tax parameter $\gamma$.

For typical wealth tax rates (here: $\tau_{\omega}=0.01$ ) the impact of wealth taxation on the aftertax discount rate is rather small. Consequently, variations of the fraction $\gamma$ of financial assets that is subject to wealth taxation do not affect the present value of cash flows and wealth tax payments as much as under higher wealth tax rates (here: $\tau_{\omega}=0.02$ ). In the latter case, lower after-tax discount rates due to higher values of $\gamma$ increase the present value of wealth tax payments relatively more than the present value of cash flows. For

\footnotetext{
${ }^{34}$ Studies that identify apparently paradoxical profit tax effects on the timing of risky investments in non-depreciable assets like land or corporate stock are, e.g., Schneider and Sureth (2010) and Gries et al. (2012).
} 
lower pre-tax interest rates $(r<0.04)$ paradoxical reactions are even more likely to occur. For example, if $r=0.02$ already a wealth tax rate of $0.6 \%$ induces paradoxical timing effects.

Besides $\gamma$, we have identified the wealth tax rate $\tau_{\omega}$ to be an important driver of ambiguous outcomes. Only if the default alternative is wealth tax-exempt or if the investor uses an exogenous time preference rate $\psi$ for discounting, increasing the wealth tax rate induces unambiguous effects.

Proposition 5 For a wealth tax-exempt default alternative $(\gamma=0)$ or if an individual time preference rate $\psi$ is used for discounting increasing the wealth tax rate always induces normal effects.

\section{Proof.}

$$
\left.\frac{\partial \pi_{0}^{H C}}{\partial \tau_{\omega}}\right|_{\gamma=0}=\frac{\beta_{\tau}}{\beta_{\tau}-1} \cdot \frac{r_{\tau}-\alpha}{1-\tau_{\pi}} \cdot \frac{\bar{W}_{H C}}{r\left(1-\tau_{r}\right)+\delta_{\omega}}>0
$$

To illustrate the forces at work Figure 2 displays the critical investment threshold as a function of the wealth tax rate $\tau_{\omega}$ for $\gamma=1$ (solid line) and $\gamma=0$ (dashed line). For $\delta_{\omega}=0$ (constant tax value of the project) we observe normal wealth tax effects. Hence, the critical investment threshold increases with increasing wealth tax rate. This result also holds in the limiting case of certainty $\left(\sigma^{2}=0\right) .{ }^{35}$

\footnotetext{
${ }^{35}$ The assumption $\alpha=0$ in our numerical example implies that in expected value terms the cash flows are constant over time. Figure 2 thus illustrates the special case of an approximization of an economic depreciation for $\delta_{\omega}=0$. Furthermore, also appreciations in the option value at any point in time would have to be recognized by economic depreciation as outlined in Niemann (1999b).
} 


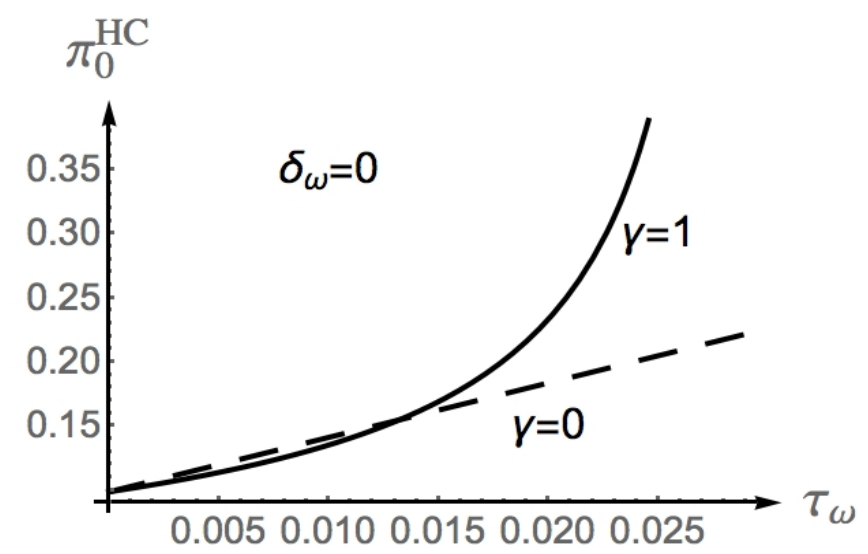

Figure 2: Critical investment threshold under historical cost accounting as a function of the wealth tax rate $\tau_{\omega}$

By contrast, if the tax law permits sufficiently high depreciation deductions for wealth tax purposes, the present value of wealth tax payments decreases, which lowers the critical investment threshold. Positive capital depreciation allowances are common for depreciable assets in most countries that levy a wealth tax. Usually, they correspond to depreciation allowances used for profit tax purposes. The ambiguous tax effects that arise if depreciation allowances reduce the wealth tax base are depicted in Figure 3, which also displays the critical investment threshold as a function of the wealth tax rate $\tau_{\omega}$ for $\gamma=1$ (solid line) and $\gamma=0$ (dashed line). For $\delta_{\omega}=\delta_{\pi}=0.3$, we observe a normal tax effect for $\gamma=0$ and a paradoxical tax effect for $\gamma=1$. The neutral values of depreciation deductions for which neither a normal nor a paradoxical tax effect occurs, are derived in section 4 .

The paradoxical effect arises because a higher wealth tax rate reduces the after-tax discount rate, increasing the present value of cash flows more than the present value of wealth tax payments. 


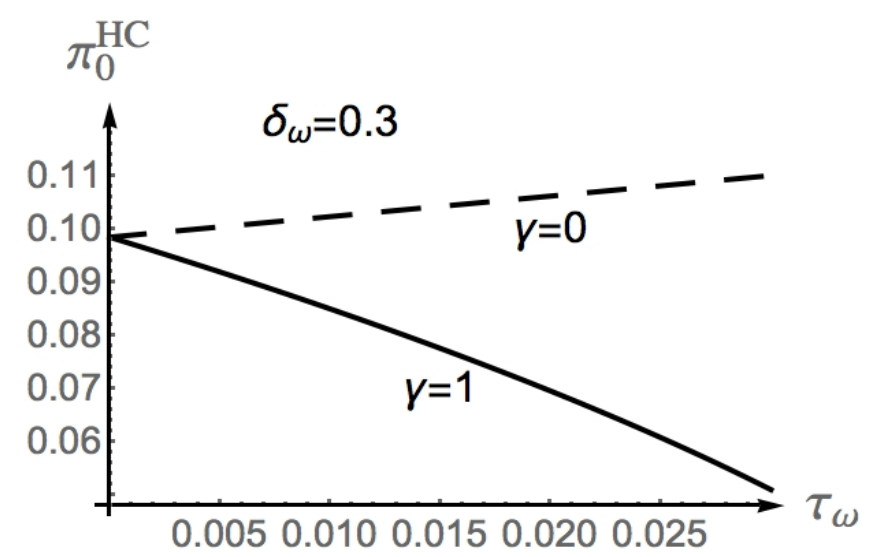

Figure 3: Critical investment threshold under historical cost accounting as a function of the wealth tax rate $\tau_{\omega}$

The results presented in Figures 2 and 3 do not change fundamentally if the profit tax is completely replaced by the wealth tax, i.e., $\tau_{\pi}=\tau_{r}=0, \tau_{\omega}>0$ and $r_{\tau}=r-\gamma \tau_{\omega}$, as can be observed from Figures 4 and 5. We can regard the abolition of profit taxation as an extreme interpretation of raising wealth taxes. These numerical examples show the impact of the wealth tax rate $\tau_{\omega}$ on the critical investment threshold, provided that profit taxes are not levied. Again, the parameter setting is given by $r=0.04, \alpha=0$, $\delta_{\omega} \in\{0,0.3\}, \gamma \in\{0,1\}, \sigma=0.3$.

It turns out that the wealth tax effects are roughly similar to a scenario with profit taxation. However, abolishing (introducing) profit taxation can either reduce (increase) the critical investment threshold, as can be observed by comparing Figures 2 and 4, or increase (reduce) the critical threshold as is shown by Figures 3 and 5. As a consequence, the interactions between wealth and profit taxes are parameter-dependent and furthermore depend on asset valuation. We illustrate these effects exemplarily for the case of historical cost valuation for wealth tax purposes. 


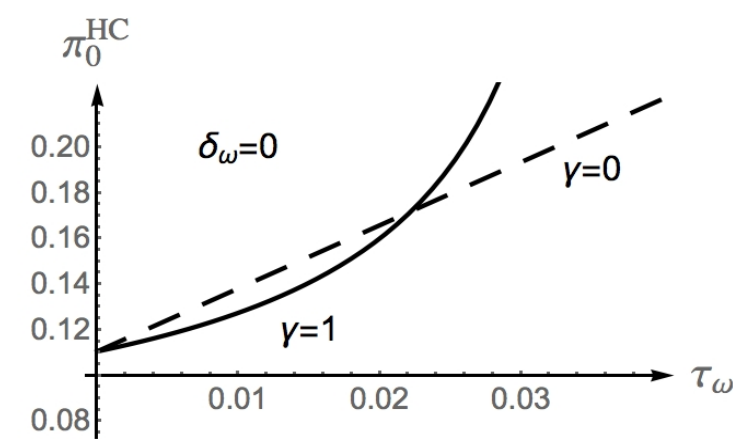

Figure 4: Critical investment threshold under historical cost accounting as a function of the wealth tax rate $\tau_{\omega}$ for $\tau_{\pi}=\tau_{r}=0$

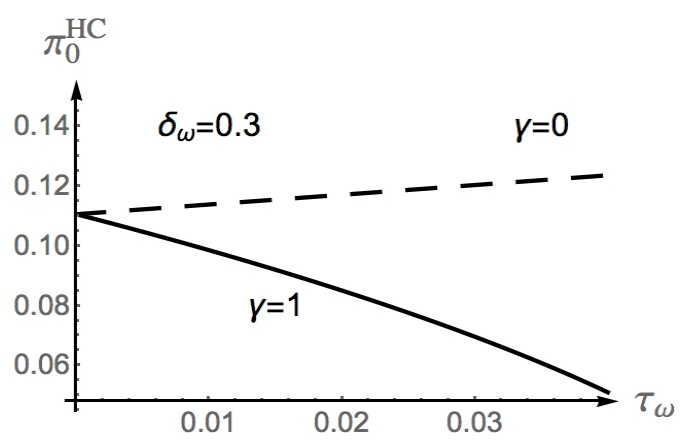

Figure 5: Critical investment threshold under historical cost accounting as a function of the wealth tax rate $\tau_{\omega}$ for

$$
\tau_{\pi}=\tau_{r}=0
$$

Again, we find paradoxical reactions for sufficiently high depreciation allowances. Summarizing our numerical findings, paradoxical wealth tax effects tend to be more likely for

- low pre-tax interest rates $r$,

- high volatility $\sigma$,

- high growth rates $\alpha$,

- high wealth tax rates $\tau_{\omega}$,

- high taxation of the default alternative $\gamma$.

\section{$4 \quad$ Neutral tax systems}

Having identified settings that lead to both normal and paradoxical reactions, it is important to figure out under what conditions such distortions can be avoided. By definition, neutral tax systems do not alter economic decisions compared to a given reference solution. In our setting a neutral tax system should leave the critical investment threshold unchanged. Since our focus is wealth taxation, but our model also includes income taxes, the necessary first step is to define an appropriate reference case. In a strict sense, the tax 
system is neutral if the pre-tax investment threshold is identical to the after-tax threshold, taking both wealth and income taxation into account.

We derived the pre-tax investment threshold $\pi_{0}^{*}=(\beta /(\beta-1))(r-\alpha)$ in eq. (32). For deriving neutral tax systems it is necessary and sufficient to equate the pre-tax and the after-tax investment thresholds and to solve for the tax parameters under consideration. As there are various tax parameters with potentially offsetting effects an infinite number of neutral tax systems may exist. Due to different investment thresholds for historical cost and fair value accounting, neutrality conditions have to distinguish between these valuation methods.

For historical cost valuation we can derive the neutrality condition by equating the critical investment thresholds from (29) and (32) and further transformation:

$$
\begin{aligned}
\pi_{0}^{*} & \stackrel{!}{=} \pi_{0}^{H C} \\
\tau_{\omega} D_{\omega}-\tau_{\pi} D_{\pi} & =\frac{\beta}{\beta-1} \cdot \frac{\beta_{\tau}-1}{\beta_{\tau}} \cdot \frac{r-\alpha}{r_{\tau}-\alpha} \cdot\left(1-\tau_{\pi}\right)-1 .
\end{aligned}
$$

This condition means that the present value of wealth taxes less the present value of tax shields due to depreciation deductions for income tax purposes must equal the constant on the right hand side. For a given depreciation rate for income tax purposes $\delta_{\pi}$, the neutrality condition (41) translates to a neutral depreciation rate for wealth tax purposes:

$$
\delta_{\omega}^{\text {neutral }}=\frac{\tau_{\omega} \bar{W}_{H C}}{\frac{\beta}{\beta-1} \cdot \frac{\beta_{\tau}-1}{\beta_{\tau}} \cdot \frac{r-\alpha}{r_{\tau}-\alpha} \cdot\left(1-\tau_{\pi}\right)-1+\frac{\tau_{\pi} \cdot \delta_{\pi}}{\delta_{\pi}+r_{\tau}}}-r_{\tau} .
$$

This neutral depreciation rate is a function of the after-tax discount rate $r_{\tau}$ and the wealth tax rate $\tau_{\omega}$. Figure 6 displays the neutral depreciation rate for $\gamma=1$ considering the example from Figures 2 and 3 with the parameters $r=0.04, \alpha=0, \sigma=0.3, \tau_{\pi}=$ $\tau_{r}=0.25, \delta_{\pi}=0.3$ 


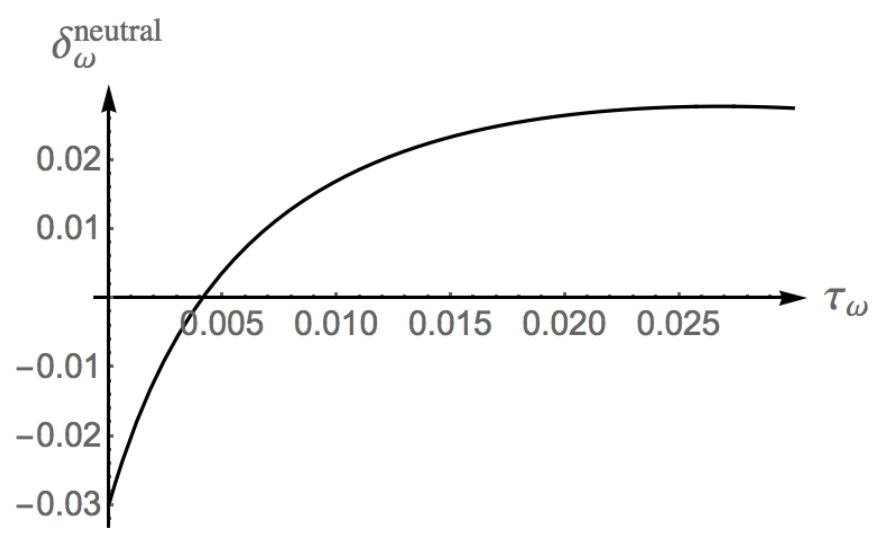

Figure 6: Neutral depreciation rate for wealth tax purposes as a function of the wealth tax rate

If the actual depreciation rate exceeds the neutral one, investment is accelerated, as is exemplarily shown in Figure 3. Otherwise, if the actual depreciation rate is below the function plotted in Figure 6, investment is delayed by increasing wealth taxation, as in Figure 2. Figure 6 also explains why Figure 2 shows normal and Figure 3 paradoxical wealth tax effects for $\gamma=1$. In contrast to models under certainty, condition (42) clarifies that it is not sufficient for neutrality to set $\delta_{\pi}$ and $\delta_{\omega}$ to the economic rate of depreciation $-\alpha$ (which is 0 in the example above). Rather, tax neutrality requires neutral taxation of the option to invest, which implies taxation of unrealized capital gains. ${ }^{36}$

The neutrality condition (41) can be further simplified only if the default alternative remains tax-exempt or if the investor uses an individual time preference rate for discounting $\left(\tau_{r}=\gamma=0, r=r_{\tau}, \beta=\beta_{\tau}\right.$ or if $\left.r_{\tau}=\psi\right):$

$$
\tau_{\omega} D_{\omega}-\tau_{\pi} D_{\pi}=-\tau_{\pi}
$$

and thus

\footnotetext{
${ }^{36}$ Since tax systems in the real world do not recognize mere business opportunities as taxable assets, the neutral treatment of the option to invest is not considered here. See Niemann (1999b) for neutral income taxation of an option to invest.
} 


$$
\tau_{\omega}=\frac{D_{\pi}-1}{D_{\omega}} \tau_{\pi}
$$

As a consequence, in neutral tax systems with depreciation deductions limited to acquisition costs $\left(D_{\pi} \leq 1\right)$ tax-exemption of the default alternative prohibits positive wealth taxation of real investment.

If the default alternative is not tax-exempt $\left(\tau_{r}>0, \gamma>0\right)$ it is always possible to find combinations of $D_{\omega}$ and $D_{\pi}$ that fulfill the neutrality condition. However, it cannot be guaranteed that these algebraic solutions are feasible within the range of real-world tax systems $\left(0 \leq D_{\pi} \leq 1\right)$. Therefore, the analytically determined neutral tax system might be only theoretically relevant and de facto impossible to be implemented in the real world.

For fair value accounting the neutrality condition can be solved with respect to the present value of depreciation deductions for income tax purposes.

$$
\begin{aligned}
\pi_{0}^{*} & \stackrel{!}{=} \pi_{0}^{F V}, \\
D_{\pi} & =\frac{1}{\tau_{\pi}}-\frac{\beta_{0}}{\beta_{0}-1} \cdot \frac{\beta-1}{\beta} \cdot \frac{r-\alpha}{\tau_{\pi}} \cdot \frac{\rho\left(1-\tau_{\pi}\right)\left(r_{\tau}+\delta_{\omega}\right)-\tau_{\omega}\left(r_{\tau}-\alpha\right)}{\rho\left(r_{\tau}-\alpha\right)\left(r_{\tau}+\delta_{\omega}\right)} \\
& =\frac{1}{\tau_{\pi}}-\frac{\beta_{0}}{\beta_{0}-1} \cdot \frac{\beta-1}{\beta} \cdot \frac{r-\alpha}{\tau_{\pi}} \cdot\left[\frac{1-\tau_{\pi}}{r_{\tau}-\alpha}-\frac{\tau_{\omega}}{\rho\left(r_{\tau}+\delta_{\omega}\right)}\right] .
\end{aligned}
$$

Again, for a tax-exempt default alternative $\left(r_{\tau}=r\right.$ or $\left.r_{\tau}=\psi\right)$ a neutral depreciation schedule is not feasible within the range of traditional tax systems, because the present value of depreciation deductions exceeds the acquisition costs:

$$
\left.D_{\pi}\right|_{\tau_{r}=\gamma=0}=1+\frac{\tau_{\omega}}{\tau_{\pi}} \cdot \frac{r-\alpha}{\rho\left(r_{\tau}+\delta_{\omega}\right)}>1 \quad\left(\text { for } \delta_{\omega}>-r_{\tau}\right)
$$

More general neutrality conditions could be derived if the option to invest would be regarded as an asset for wealth tax purposes. In this case the Johansson-Samuelson theorem would apply. ${ }^{37}$

\footnotetext{
${ }^{37}$ See Samuelson (1964), Johansson (1969).
} 


\section{Conclusions and implications}

We analyze the impact of wealth taxation on investment timing decisions under uncertainty and irreversibility. From the variety of wealth tax parameters only a few induce unambiguous results. As could be expected, higher initial values of a project for tax purposes delay investment. This result holds for historical cost valuation as well as for fair value accounting. Which one of these valuation methods tends to accelerated (or less delayed) investment is ambiguous and depends upon the initial value. Moreover, higher depreciation rates for wealth tax purposes corresponding to a lower subsequent valuation also accelerate investment. In this respect we identify normal effects only.

By contrast, the wealth tax rate as well as the wealth tax treatment of the default alternative can induce either normal or apparently paradoxical investment timing effects. For a sufficiently low valuation of a project due to a low initial tax value or high depreciation rates for wealth tax purposes, higher wealth tax rates can accelerate investment. Otherwise, the normal effect occurs and higher wealth tax rates delay investment. Higher wealth taxation of the default alternative can delay investment if the wealth tax rate is sufficiently high so that the present value of wealth tax payments increases more than the project value. Otherwise, the resulting normal tax effect means that higher taxation of the default alternative favors accelerated investment. We find that apparently paradoxical wealth tax effects (delay upon a wealth tax rate decrease) are more likely for low interest rates and for high-risk investments. Furthermore, we derive conditions for an investment neutral wealth tax that avoids such distortions. Whether and how often a normal or a paradoxical tax effect prevails is an empirical question and depends on the above-mentioned wealth tax parameters as well as the pre-tax interest rate and the expected cash flows of the investment project.

These results indicate that the tax legislator should be aware of the opposing effects of wealth taxation on different types of projects prior to tax reforms. Estimations of 
revenues, as well as the redistributional potential of a wealth tax can only be meaningful if the investment effects are anticipated correctly. It is doubtful whether the tax legislator's objectives can be reached by wealth-related taxes. We show that tax neutrality requires project-specific depreciation rules that are difficult to implement from the perspective of legal certainty. It is therefore highly likely that wealth taxation has real economic effects. If the tax legislator intends to favor the realization of particular projects, it will depend on the economic parameters whether this aim or its opposite will be reached. If the tax legislator tries to prevent taxpayers from certain economic activities, for example, car usage, our examples show that wealth taxes are neither an accurate tax policy device to do so, nor will they necessarily imply an increase in revenues.

Of course, our analysis is subject to several limitations. Whereas the current tax policy discussion is centered on distributive considerations, our model does not permit conclusions regarding the distribution of wealth after the introduction of a wealth tax. Due to our assumption of equity financing, financial constraints and liquidity considerations are disregarded in the model. The revenue consequences of a wealth tax cannot be inferred from our results. This is because we take an individual rather than a macro perspective and focus on purely domestic investment. Investigating aggregate effects of wealth taxation would require extensive assumptions beyond the scope of our model, such as a social discount rate or the usage of tax revenues, even if all investors were homogenous. Therefore, we delegate aggregate as well as distributive effects to future research.

Moreover, compliance costs, which are often assumed substantial for wealth taxes are disregarded here. Our model is able to predict the investment timing effects of one type of wealth-related taxation, but not the combined effects of either different capital taxes levied simultaneously or of differential tax rates for different types of assets. For reasons of mathematical simplicity our model is limited to a perpetual option to invest. Presuming a finite option lifetime and hence reduced option value we would expect less distinctive results. Furthermore, we assume a full and complete loss offset. Relaxing this 
assumption is likely to generate tax-induced delays more often. ${ }^{38}$ Whereas income taxes can be regarded as variable costs, wealth taxes are fixed costs. It is therefore likely that income taxation shifts more risk from the investor to the fiscal authorities than wealth taxes. However, our model does not permit a formal proof of this conjecture. In contrast to our setting with risk neutral investors, investors are often considered risk averse. In principle, contingent claims analysis would allow us to abstract from risk aversion and use risk neutral valuation in real option approaches. Unfortunately, this approach requires the spanning property and a sophisticated Tax-CAPM that addresses the different risk profiles and taxation of the underlying and the options adequately. For our setting the integration of risk aversion still comprises a bunch of unsolved theoretical caveats. ${ }^{39}$

In the light of the ongoing discussion on the introduction or increase of wealth-related taxes in several countries despite the well-known inefficiencies of these taxes, it is evident that the impact of wealth taxation on investments in risky projects is uncertain. Accounting for normal and paradoxical outcomes at the same time might impact economic growth negatively. Additional uncertainty arises not only because of frequent tax reforms but because of the risks involved in the valuation procedures and strictly project-dependent investment effects of a wealth tax. This might wind down investors' propensity to carry out risky projects. Empirical tests are needed to learn more about the likelihood of normal and paradoxical outcomes and the magnitude of the identified tax effects. In further research our model should be extended with respect to stochastic wealth taxes. For example, wealth tax payments - and not only cash flows - should be considered as a stochastic process as valuation in practice often turns out to be a de facto random endeavor.

\footnotetext{
${ }^{38}$ See Mehrmann, Schneider, and Sureth (2012) who study timing decisions under asymmetric taxation of gains and losses and identify conditions for higher taxes to increase investors' propensity to invest early. For the effects of asymmetric taxation in a real options model with an imputation tax system see Panteghini (2005).

${ }^{39}$ See Niemann and Sureth (2004) who investigate neutral profit taxation under risk aversion.
} 


\section{References}

Agliardi, E. (2001). Taxation and Investment Decisions: A Real Options Approach. Australian Economic Papers, 40, 44-55. doi:10.1111/1467-8454.00112

Allee, K. D., Lynch, D. P., Petroni, K. R., \& Schroeder, J. H. (2015). Do Property Taxes Affect Real Operating Decisions and Market Prices for Crude Oil? Contemporary Accounting Research, 32, 736-762. doi:10.1111/1911-3846.12086

Alvarez, L. H. R., \& Koskela, E. (2008). Progressive Taxation, Tax Exemption, and Irreversible Investment under Uncertainty. Journal of Public Economic Theory, 10, 149-169. doi:10.1111/j.1467-9779.2008.00356.x

Arnott, R. (2005). Neutral Property Taxation. Journal of Public Economic Theory, 7, 27-50. doi:10.1111/j.1467-9779.2005.00192.x

Arnott, R., \& Petrova, P. (2006). The Property Tax on Value: Deadweight Loss. International Tax and Public Finance, 13, 241-266. doi:10.3386/w8913

Arslan, Y., Atabek, A., Hulagu, T., \& Şahinöz, S. (2015). Expectation Errors, Uncertainty, and Economic Activity. Oxford Economic Papers, 67, 634-660. doi:10.1093/oep /gpv003

Atkinson, A. B. (1971). Capital Taxes, the Redistribution of Wealth and Individual Savings. Review of Economic Studies, 38, 209-227. doi:10.2307/2296780

Atkinson, T., Piketty, T., \& Saez, E. (2011) Top Incomes in the Long Run of History. Journal of Economic Literature, 49, 3-71. doi:10.1257/jel.49.1.3

Auerbach, A. J. \& Hassett, K. (2015). Capital Taxation in the Twenty-First Century. American Economic Review, 105, 38-42. doi:10.1257/aer.p20151058

Bach, S., Beznoska, M., \& Steiner, V. (2014). A Wealth Tax on the Rich to Bring down Public Debt? The Journal of Applied Public Economics, 35, 67-89. doi:10.1111/j.14755890.2014.12023.x

Bachmann, R., Caballero, R. J., \& Engel, E. M. R. A. (2013). Aggregate Implications of Lumpy Investment: New Evidence and a DSGE Model. American Economic Journal: Macroeconomics, 5, 29-67. doi:10.1257/mac.5.4.29

Balogh, T. (1964). A Note on the Wealth Tax. The Economic Journal, 74, 221-224. doi: $10.2307 / 2228157$ 
Bar-Ilan, A., \& Strange, W. C. (1996). Investment Lags. American Economic Review, 86, 610-622. Retrieved from http://www.jstor.org/stable/2118214

Bentick, B. L. (1979). The Impact of Taxation and Valuation Practices on Timing and Efficiency of Land Use. Journal of Political Economy, 87, 859-868. doi:10.1086/260797

Bird, R. M. (1991). The Taxation of Personal Wealth in International Perspective. Canadian Public Policy, 17, 322-334. doi:10.2307/3551639

BMF (2013). Die wichtigsten Steuern im internationalen Vergleich. Berlin: Bundesministerium der Finanzen.

Brennan, G., \& Nellor, D. (1982). Wealth, Consumption and Tax Neutrality. National Tax Journal, 35, 427-436. Retrieved from http://www.jstor.org/stable/41862456

Burbidge, J. (1991). The Allocative and Efficiency Effects of Wealth Taxes. Canadian Public Policy, 17, 264-278. doi:10.2307/3551636

Cnossen, S., \& Bovenberg, L. (2001). Fundamental Tax Reform in The Netherlands. International Tax and Public Finance, 8, 471-484. doi:10.1023/A:1011287428702

Craft, E. D., \& Schmidt, R. M. (2005). An Analysis of the Effects of Vehicle Property Taxes on Vehicle Demand. National Tax Journal, 58, 697-720. Retrieved from http://www.jstor.org/stable/41790299

Damodaran, A. (2011). The Little Book of Valuation. New York City, NY: Wiley.

Davies, J. B. (1991). The Distributive Effects of Wealth Taxes. Canadian Public Policy, 17, 279-308. doi:10.2307/3551637

Dixit, A. K., \& Pindyck, R. S. (1994). Investment under Uncertainty. Princeton, NJ: Princeton University Press.

Dye, R. F., McGuire, T. G., \& Merriman, D. F. (2001). The Impact of Property Taxes and Property Tax Classification on Business Activity in the Chicago Metropolitan Area. Journal of Regional Science, 41, 757-777. doi:10.1111/0022-4146.00242

Edson, C. (2012). The Capital Constraining effects of the Norwegian Wealth Tax (Discussion Papers No. 724). Oslo: Statistics Norway Research Department. Retrieved from https://www.ssb.no/a/publikasjoner/pdf/DP/dp724.pdf

EY (2014a). Worldwide Corporate Tax Guide 2014. London: EYGM. 
EY (2014b). Worldwide Personal Tax Guide. Income Tax, Social Security and Immigration 2013-2014. London: EYGM.

Fisher, I. (1930). The Theory of Interest, reprint of New York 1930: The Macmillan, New York 1970: Augustus M. Kelley.

Georgi, A. A. (1994). Steuern in der Investitionsplanung: eine Analyse der Entscheidungsrelevanz von Ertrag- und Substanzsteuern. Hamburg: S+W Steuer- und Wirtschaftsverlag.

Glennerster, H. (2012). Why Was a Wealth Tax for the UK Abandoned? Lessons for the Policy Process and Tackling Wealth Inequality. Journal of Social Policy, 41, 233-249. doi:10.1017/S0047279411000602

Grenadier, S. R. (1996). The Strategic Exercise of Options: Development Cascades and Overbuilding in Real Estate Markets. Journal of Finance, 51, 1653-1679. doi:10.1111/j.1540-6261.1996.tb05221.x

Grenadier, S. R. (2002). Option Exercise Games: An Application to the Equilibrium Investment Strategies of Firms. Review of Financial Studies, 15, 691-721. doi:10.1093/rfs/15.3.691

Grenadier, S. R., \& Wang, N. (2005). Investment Timing, Agency, and Information. Journal of Financial Economics, 75, 493-533. doi:10.1016/j.jfineco.2004.02.004

Gries, T., Prior, U., \& Sureth, C. (2012). A Tax Paradox for Investment Decisions under Uncertainty. Journal of Public Economic Theory, 14, 521-545. doi:10.1111/j.14679779.2012.01547.x

Hansson, A. (2008). The Wealth Tax and Entrepreneurial Activity. Journal of Entrepreneurship, 17, 137-156. doi:10.1177/097135570801700203

Hirshleifer, J. (1958). On the Theory of Optimal Investment Decisions. Journal of Political Economy, 66, 329-352. doi:10.1086/258057

Hoppe, T., Maiterth, R., \& Sureth, C. (2015). Vermögensteuer und ihre Implikationen für den Wirtschaftsstandort Deutschland - eine betriebswirtschaftliche Analyse (Discussion Paper No. 181). Berlin: arqus Quantitative Research in Taxation. Retrieved from http://www.arqus.info/mobile/paper/arqus_181.pdf, available at SSRN: http://ssrn.com/abstract=2548398 or http://dx.doi.org/10.2139/ssrn.2548398 IBFD (2015). Tax Research Database. Amsterdam: IBFD. 
IMF (2013). World Economic and Financial Surveys: Fiscal Monitor - Taxing Times. Washington, DC: International Monetary Fund.

IMF (2014). Fiscal Policy and Income Inequality. IMF Policy Paper. Washington, DC: International Monetary Fund.

Johansson, S.-E. (1969). Income Taxes and Investment Decisions. Swedish Journal of Economics, 71, 104-110. Retrieved from http://www.jstor.org/stable/3438990.

Keuschnigg, C., Fortin, I., Schönpflug, K., Schuster, P., Schwab, T., \& Schwarzbauer, W. (2013). Zur Besteuerung von Vermögen in Österreich. Aufkommen, Verteilung und ökonomische Effekte. Vienna: Institute for Advanced Studies. Retrieved from https://www.ihs.ac.at/publications/lib/IHSPR6031081.pdf

King, M. A., \& Fullerton, D. (1984). The Taxation of Income from Capital. A Comparative Study of the United States, the United Kingdom, Sweden, and West Germany. Chicago, IL, London: University of Chicago Press. doi:10.2307/2553883

Kocherlakota, N. R. (2005). Zero Expected Wealth Taxes: A Mirrlees Approach to Dynamic Optimal Taxation. Econometrica, 73, 1587-1621. doi:10.1111/j.14680262.2005.00630.x

KPMG (2012a). KPMG's Individual Income Tax and Social Security Rate Survey 2012. kpmg.com/socialmedia: KPMG International.

KPMG (2012b). Vermögensteuer - wer besteuert wie? Frankfurt a.M.: KPMG.

Laux, C. (2012). Financial Instruments, Financial Reporting, and Financial Stability. Accounting and Business Research, 42, 239-260. doi:10.1080/00014788.2012.681857

Laux, C., \& Leuz, C. (2009). The Crisis of Fair-Value Accounting: Making Sense of the Recent Debate. Accounting, Organizations and Society, 34, 826-834. doi:10.1016/j.aos. 2009.04.003

Laux, C., \& Leuz, C. (2010). Did Fair-Value Accounting Contribute to the Financial Crisis? Journal of Economic Perspectives, 24, 93-118. doi:10.1257/jep.24.1.93

Maiterth, R., \& Houben, H. (2012). Vermögensbesteuerung aus ökonomischer Sicht. In J. Hey, R. Maiterth, \& H. Houben (Eds..), Zukunft der Vermögensbesteuerung. IFSt Schrift Nr. 483 (pp. 87-134). Berlin: Institut für Finanzen und Steuern. 
McDonald, R. L., \& Siegel, D. R. (1985). Investment and the Valuation of Firms when there is an Option to Shut Down. International Economic Review, 26, 331-349. doi: $10.2307 / 2526587$

Mellwig, W. (1985). Investition und Besteuerung. Wiesbaden: Gabler.

Merton, R. C. (1973). Theory of Rational Option Pricing. Bell Journal of Economics, 4, 141-183. doi:10.2307/3003143

Mehrmann, A., Schneider, G., \& Sureth, C. (2012). Asymmetric Taxation of Profits and Losses and its Influence on Investment Timing: Paradoxical Effects of Tax Increases. (Discussion Paper No. 134). Berlin: arqus, Quantitative Research in Taxation. Retrieved from http://www.arqus.info/mobile/paper/arqus_134.pdf, available at SSRN: http://ssrn.com/abstract=2111475 or http://dx.doi.org/10.2139/ssrn.2111475

Michalos, A. C. (1988). A Case for a Progressive Annual Net Wealth Tax. Public Affairs Quarterly, 2, 105-140. Retrieved from http://www.jstor.org/stable/40435679

Mieszkowski, P. (1972). The Property Tax: an Excise Tax or a Profits Tax? Journal of Public Economics, 1, 73-96. doi:10.1016/0047-2727(72)90020-5

Mills, D. E. (1981). The Non-Neutrality of Land Value Taxation. National Tax Journal, 34, 125-129. Retrieved from http://www.jstor.org/stable/41862356

Mintz, J. M. (1991). The Role of Wealth Taxation in the Overall Tax System. Canadian Public Policy, 17, 248-263. doi:10.2307/3551635

Müller, J. (2014). The Challenge of Assessing the Market Value of Private Companies Using a Standardized Combination Method for Tax Purposes - Lessons to be Learned from Past Experience. European Accounting Review, 23, 117-141. doi:10.1080/09638180.2012.746528

Müller, J., \& Sureth, C. (2011). Marktnahe Bewertung von Unternehmen nach der Erbschaftsteuerreform? Zeitschrift für betriebswirtschaftliche Forschung, 63, Special Issue $63 / 11,45-83$.

Musumeci, J. J., \& Sansing, R. C. (2014): Corporate Tax Preferences: Identification and Accounting Measurement. Journal of the American Taxation Association, 36, 89-103. doi:10.2308/atax-50557 
Niemann, R. (1999a). Investitionsneutrale Steuersysteme unter Unsicherheit - Eine realoptionstheoretische Analyse. Zeitschrift für Wirtschafts- und Sozialwissenschaften, 119, 251-371. Retrieved from https://www.wiso-net.de:443/document/BLIS__ 19 993351093851885920591451851121

Niemann, R. (1999b). Neutral Taxation under Uncertainty. FinanzArchiv, 56, 51-66. Retrieved from http://www.jstor.org/stable/40912867

Niemann, R., \& Sureth, C. (2004). Tax Neutrality under Irreversibility and Risk Aversion. Economics Letters, 84, 43-47. doi:10.1016/j.econlet.2003.12.010

Niemann, R., \& Sureth, C. (2005). Capital Budgeting with Taxes under Uncertainty and Irreversibility. Journal of Economics and Statistics, 225, 77-95. Retrieved from http://www.jstor.org/stable/23813278

Niemann, R., \& Sureth, C. (2013). Sooner or Later? - Paradoxical Investment Effects of Capital Gains Taxation under Simultaneous Investment and Abandonment Flexibility. European Accounting Review, 22, 367-390. doi:10.1080/09638180.2012.682781

OECD (2014). Revenue Statistics, 1965-2013. Paris: OECD. doi:10.1787/rev_stats2014-en-fr

OECD (2015). In It Together: Why Less Inequality Benefits All. Paris: OECD. doi:10.1787 /9789264235120-en

Panteghini, P. M. (2001). Dual Income Taxation: The Choice of the Imputed Rate of Return. Finnish Economic Papers, 14, 5-13. Retrieved from http://www.taloustieteelli nenyhdistys.fi/images/stories/fep/f2001_1a.pdf

Panteghini, P. M. (2004). Wide versus Narrow Tax Bases under Optimal Investment Timing. FinanzArchiv, 60, 482-493. Retrieved from http://www.jstor.org/stable/4 0913055

Panteghini, P. M. (2005). Asymmetric Taxation under Incremental and Sequential Investment. Journal of Public Economic Theory, 7, 761-779. doi:10.1111/j.14679779.2005.00243.x

Pennings, E. (2000). Taxes and Stimuli of Investment under Uncertainty. European Economic Review, 44, 383-391. doi:10.1016/S0014-2921(98)00078-6

Piketty, T. (2014). Capital in the Twenty-First Century. Cambridge, MA, London: Harvard University Press. 
Piketty, T., \& Saez, E. (2003). Income Inequality in the United States, 1913-1998. Quarterly Journal of Economics, 118, 1-39. doi:10.1162/00335530360535135

Riddick, L. A. \& Whited, T. M. (2009). The Corporate Propensity to Save. Journal of Finance, 64, 1729-1766. doi:10.1111/j.1540-6261.2009.01478.x

Ristea, L., \& Trandafir, A. (2010). Wealth Tax within Europe in the Context of a Possible Implementation in Romania - The Existing Wealth Tax and its Decline in Europe. Annals of the University of Petroşani, Economics, 10, 299-306. Retrieved from http://upet.ro/annals/economics/pdf/2010/20100228.pdf

Saez, E., \& Veall, M. (2005). The Evolution of High Income in Northern America. Lessons from Canadian Evidence. American Economic Review, 95, 831-849. doi:10.1 $257 / 0002828054201404$

Samuelson, P. A. (1964). Tax Deductibility of Economic Depreciation to Ensure Invariant Valuations, Journal of Political Economy 72, 604-606. Retrieved from http://www.jstor.org/stable/1829466.

Schneider, G., \& Sureth, C. (2010). Capitalized Investments with Entry and Exit Options and Paradoxical Tax Effects. Review of Managerial Science, 4, 149-169. doi:10.1007/s 11846-010-0040-7

Schratzenstaller, M. (2011). Vermögensbesteuerung - Chancen, Risiken und Gestaltungsmöglichkeiten. Bonn: Abteilung Wirtschafts- und Sozialpolitik der FriedrichEbert-Stiftung.

Siegel, T. (1982). Steuerwirkungen und Steuerpolitik in der Unternehmung. Würzburg et al.: Physica.

Spengel, C., Evers L., \& Evers, M. T. (2013). Probleme einer Vermögensteuer in Deutschland: Eine ökonomische Analyse. DIW-Vierteljahrshefte zur Wirtschaftsforschung, 82, 129-146. doi:10.3790/vjh.82.1.129

Stiglitz, J. E. (1969). The Effects of Income, Wealth, and Capital Gains Taxation on Risk-Taking. The Quarterly Journal of Economics, 83, 263-283. Retrieved from http://www.jstor.org/stable/1883083

Sureth, C. (1999). Der Einfluss von Steuern auf Investitionsentscheidungen bei Unsicherheit. Wiesbaden: Deutscher Universitäts-Verlag. 
Sureth, C. (2002). Partially Irreversible Investment Decisions and Taxation under Uncertainty - a Real Option Approach. German Economic Review, 3, 185-221. doi:10.1111/ 1468-0475.00057

Sureth, C., \& Maiterth, R. (2008). The Impact of Minimum Taxation by an Imputable Wealth Tax on Capital Budgeting and Business Strategy of German Companies. Review of Managerial Science, 2, 80-110. doi:10.1007/s11846-008-0016-z

Thurow, L. C. (1972). Net Worth Taxes. National Tax Journal, 25, 417-423. Retrieved from http://web.a.ebscohost.com/ehost/pdfviewer/pdfviewer?sid=fa0b1f0c6454-436 3-8ced-cece468fa213\%40sessionmgr4001\&vid=4\&hid=4109

Verfassungsgerichtshof Österreich (2007). Court Decision on the Austrian Estate Tax and Gift Tax. Reference Numbers VfGH 7.3.2007, G 54/06, and VfGH 15.6.2007, G 23/07.

Vlassenko, I. (2001). Evaluation of the efficiency and fairness of British, French and Swedish property tax systems. Property Management, 19, 384-416. doi:10.1108/EUM0000000006239

Wagner, F. W., \& Dirrigl, H. (1980). Die Steuerplanung der Unternehmung. Stuttgart et al.: Fischer.

Weeds, H. (2002). Strategic Delay in a Real Options Model of R\&D Competition. Review of Economic Studies, 69, 729-747. doi:10.1111/1467-937X.t01-1-00029.

Wijnbergen, S. v., \& Estache, A. (1999). Evaluating the Minimum Asset Tax on Corporations: an Option Pricing Approach. Journal of Public Economics, 71, 75-96. doi:10.1016/S0047-2727(98)00050-4 


\section{Appendix}

To describe in more detail which conditions induce normal or paradoxical tax effects, we compute the partial derivatives $\partial \pi_{0}^{H C} / \partial \tau_{\omega}$ and $\partial \pi_{0}^{H C} / \partial \gamma$ in some limiting cases.

The critical investment threshold for historical cost accounting is given by

$$
\pi_{0}^{H C}=\frac{\beta_{\tau}}{\beta_{\tau}-1} \cdot \frac{r_{\tau}-\alpha}{1-\tau_{\pi}} \cdot\left(1-\tau_{\pi} \frac{\delta_{\pi}}{r_{\tau}+\delta_{\pi}}+\tau_{\omega} \frac{\bar{W}_{H C}}{r_{\tau}+\delta_{\omega}}\right)
$$

To compute the partial derivatives with respect to $\tau_{\omega}$ and $\gamma$ we use the substitutions

$$
\begin{aligned}
f & =\frac{\beta_{\tau}}{\beta_{\tau}-1}, \\
g & =\frac{r_{\tau}-\alpha}{1-\tau_{\pi}} \\
h & =1-\tau_{\pi} \frac{\delta_{\pi}}{r_{\tau}+\delta_{\pi}}+\tau_{\omega} \frac{\bar{W}_{H C}}{r_{\tau}+\delta_{\omega}},
\end{aligned}
$$

so that the critical investment threshold can be written as $\pi_{0}^{H C}=f \cdot g \cdot h$. Consequently, we have

$$
\frac{\partial \pi_{0}^{H C}}{\partial \tau_{\omega}}=\frac{\partial f}{\partial \tau_{\omega}} \cdot g \cdot h+f \cdot \frac{\partial g}{\partial \tau_{\omega}} \cdot h+f \cdot g \cdot \frac{\partial h}{\partial \tau_{\omega}},
$$

with

$$
\begin{aligned}
\frac{\partial f}{\partial \tau_{\omega}} & =\frac{\gamma}{\sigma^{2}\left(\beta_{\tau}-1\right)^{2}\left(\beta_{\tau}-\frac{1}{2}+\frac{\alpha}{\sigma^{2}}\right)} \geq 0 \\
\frac{\partial g}{\partial \tau_{\omega}} & =\frac{-\gamma}{1-\tau_{\pi}} \leq 0, \\
\frac{\partial h}{\partial \tau_{\omega}} & =\frac{\bar{W}_{H C}\left[r\left(1-\tau_{r}\right)+\delta_{\omega}\right]}{\left(r_{\tau}+\delta_{\omega}\right)^{2}}-\frac{\gamma \tau_{\pi} \delta_{\pi}}{\left(r_{\tau}+\delta_{\pi}\right)^{2}} \gtreqless 0 .
\end{aligned}
$$

Substitution and further transformation yields

$$
\begin{aligned}
\frac{\partial \pi_{0}^{H C}}{\partial \tau_{\omega}}= & \underbrace{\left(1-\frac{\tau_{\pi} \delta_{\pi}}{r_{\tau}+\delta_{\pi}}+\frac{\tau_{\omega} \bar{W}_{H C}}{r_{\tau}+\delta_{\omega}}\right) \cdot \frac{\gamma}{1-\tau_{\pi}}[\underbrace{\frac{r_{\tau}-\alpha}{\sigma^{2}\left(\beta_{\tau}-1\right)^{2}\left(\beta_{\tau}-\frac{1}{2}+\frac{\alpha}{\sigma^{2}}\right)}}_{>0}-\underbrace{\frac{\beta_{\tau}}{\beta_{\tau}-1}}_{>0}]}_{\geq 0} \\
& +\underbrace{\frac{\beta_{\tau}}{\beta_{\tau}-1} \cdot \frac{r_{\tau}-\alpha}{1-\tau_{\pi}}}_{>0} \underbrace{\left.\frac{\bar{W}_{H C}\left[r\left(1-\tau_{r}\right)+\delta_{\omega}\right]}{\left(r_{\tau}+\delta_{\omega}\right)^{2}}-\frac{\gamma \tau_{\pi} \delta_{\pi}}{\left(r_{\tau}+\delta_{\pi}\right)^{2}}\right]}_{>0} .
\end{aligned}
$$


Although this expression is too complicated for a general discussion, it is possible to derive the algebraic sign of the partial derivative for some limiting cases.

Proposition 6 In the limiting case of no uncertainty $(\sigma \rightarrow 0)$, the effect of increasing the capital tax rate is indeterminate.

\section{Proof.}

$$
\begin{aligned}
\lim _{\sigma \rightarrow 0} \frac{\partial \pi_{0}^{H C}}{\partial \tau_{\omega}}= & \frac{1}{1-\tau_{\pi}}\left(-\gamma-\frac{\bar{W}_{H C} \gamma \tau_{\omega}}{r_{\tau}+\delta_{\omega}}+\frac{\gamma \tau_{\pi} \delta_{\pi}}{r_{\tau}+\delta_{\pi}}\right) \\
& +\frac{r_{\tau}-\alpha}{1-\tau_{\pi}}\left[\frac{\bar{W}_{H C}\left[r\left(1-\tau_{r}\right)+\delta_{\omega}\right]}{\left(r_{\tau}+\delta_{\omega}\right)^{2}}-\frac{\gamma \tau_{\pi} \delta_{\pi}}{\left(r_{\tau}+\delta_{\pi}\right)^{2}}\right] \\
= & \underbrace{g}_{>0}(\underbrace{\frac{\partial h}{\partial \tau_{\omega}}}_{\geqq 0}-\underbrace{\frac{\gamma \cdot h}{r_{\tau}-\alpha}}_{\geq 0}) .
\end{aligned}
$$

Proposition 7 In the limiting case of uncertainty approaching infinity $(\sigma \rightarrow \infty)$, the effect of increasing the capital tax rate is indeterminate.

\section{Proof.}

$$
\begin{aligned}
\lim _{\sigma \rightarrow \infty} \frac{\partial \pi_{0}^{H C}}{\partial \tau_{\omega}} & =\lim _{\sigma \rightarrow \infty}\left[h \cdot\left(\frac{\partial f}{\partial \tau_{\omega}} \cdot g+f \cdot \frac{\partial g}{\partial \tau_{\omega}}\right)+f \cdot g \cdot \frac{\partial h}{\partial \tau_{\omega}}\right] \\
& =h \cdot \lim _{\sigma \rightarrow \infty}\left(\frac{\partial f}{\partial \tau_{\omega}} \cdot g+f \cdot \frac{\partial g}{\partial \tau_{\omega}}\right)+g \cdot \frac{\partial h}{\partial \tau_{\omega}} \cdot \lim _{\sigma \rightarrow \infty} f \\
& =-\frac{2 \gamma}{1-\tau_{\pi}} \cdot h+g \cdot \frac{\partial h}{\partial \tau_{\omega}} \cdot \infty \\
& =\infty \cdot \operatorname{sgn}\left[\frac{\partial h}{\partial \tau_{\omega}}\right] .
\end{aligned}
$$

The results of these extreme cases indicate that the impact of increasing the wealth tax rate largely depends on the valuation of the project as long as the default alternative is (at least partially, $0<\gamma \leq 1$ ) subject to wealth taxation. The degree of uncertainty is crucial for the likelihood of paradoxical investor reactions. 
Considering the impact of wealth taxation of the default alternative, we have a very similar partial derivative

$$
\frac{\partial \pi_{0}^{H C}}{\partial \gamma}=\frac{\partial f}{\partial \gamma} \cdot g \cdot h+f \cdot \frac{\partial g}{\partial \gamma} \cdot h+f \cdot g \cdot \frac{\partial h}{\partial \gamma}
$$

with

$$
\begin{aligned}
\frac{\partial f}{\partial \gamma} & =\frac{\tau_{\omega}}{\sigma^{2}\left(\beta_{\tau}-1\right)^{2}\left(\beta_{\tau}-\frac{1}{2}+\frac{\alpha}{\sigma^{2}}\right)} \geq 0, \\
\frac{\partial g}{\partial \gamma} & =\frac{-\tau_{\omega}}{1-\tau_{\pi}} \leq 0, \\
\frac{\partial h}{\partial \gamma} & =\frac{\tau_{\omega}^{2} \bar{W}_{H C}}{\left(r_{\tau}+\delta_{\omega}\right)^{2}}-\frac{\tau_{\omega} \tau_{\pi} \delta_{\pi}}{\left(r_{\tau}+\delta_{\pi}\right)^{2}} \gtreqless 0 .
\end{aligned}
$$

Substitution and further transformation yields

$$
\begin{aligned}
\frac{\partial \pi_{0}^{H C}}{\partial \gamma}= & \underbrace{\left(1-\frac{\tau_{\pi} \delta_{\pi}}{r_{\tau}+\delta_{\pi}}+\frac{\tau_{\omega} \bar{W}_{H C}}{r_{\tau}+\delta_{\omega}}\right) \cdot \frac{\tau_{\omega}}{1-\tau_{\pi}}}_{\geq 0}[\underbrace{\frac{r_{\tau}-\alpha}{\sigma^{2}\left(\beta_{\tau}-1\right)^{2}\left(\beta_{\tau}-\frac{1}{2}+\frac{\alpha}{\sigma^{2}}\right)}}_{>0}-\underbrace{\frac{\beta_{\tau}}{\beta_{\tau}-1}}_{>0}] \\
& +\underbrace{\tau_{\omega} \cdot \frac{\beta_{\tau}}{\beta_{\tau}-1} \cdot \frac{r_{\tau}-\alpha}{1-\tau_{\pi}}}_{\geqslant 0} \underbrace{\left[\frac{\tau_{\omega} \bar{W}_{H C}}{\left(r_{\tau}+\delta_{\omega}\right)^{2}}-\frac{\tau_{\pi} \delta_{\pi}}{\left(r_{\tau}+\delta_{\pi}\right)^{2}}\right]}_{>0} .
\end{aligned}
$$

Proposition 8 In the limiting case of pre-tax interest rates approaching infinity $(r \rightarrow$ $\infty)$, increasing the capital-taxable fraction of the default alternative always reduces the critical investment threshold.

\section{Proof.}

$$
\lim _{r \rightarrow \infty} \frac{\partial \pi_{0}^{H C}}{\partial \gamma}=\frac{-\tau_{\omega}}{1-\tau_{\pi}}<0
$$

Proposition 9 In the limiting case of no uncertainty $(\sigma \rightarrow 0)$, the effect of increasing the capital-taxable fraction of the default alternative is indeterminate. 


\section{Proof.}

$$
\begin{aligned}
\lim _{\sigma \rightarrow 0} \frac{\partial \pi_{0}^{H C}}{\partial \gamma}= & \frac{\tau_{\omega}}{1-\tau_{\pi}}\left(1+\frac{\bar{W}_{H C} \tau_{\omega}}{r_{\tau}+\delta_{\omega}}+\frac{\tau_{\pi} \delta_{\pi}}{r_{\tau}+\delta_{\pi}}\right) \\
& +\frac{\tau_{\omega}\left(r_{\tau}-\alpha\right)}{1-\tau_{\pi}}\left[\frac{\tau_{\omega} \bar{W}_{H C}}{\left(r_{\tau}+\delta_{\omega}\right)^{2}}-\frac{\tau_{\pi} \delta_{\pi}}{\left(r_{\tau}+\delta_{\pi}\right)^{2}}\right] \\
= & \underbrace{\frac{\tau_{\omega}}{1-\tau_{\pi}}}_{>0}[\underbrace{h}_{>0}-\underbrace{\left(r_{\tau}-\alpha\right) \frac{\partial h}{\partial \gamma}}_{\gtrless 0}] .
\end{aligned}
$$

Proposition 10 In the limiting case of uncertainty approaching infinity $(\sigma \rightarrow \infty)$, the effect of increasing the capital-taxable fraction of the default alternative is indeterminate.

Proof.

$$
\begin{aligned}
\lim _{\sigma \rightarrow \infty} \frac{\partial \pi_{0}^{H C}}{\partial \gamma} & =\lim _{\sigma \rightarrow \infty}\left[h \cdot\left(\frac{\partial f}{\partial \gamma} \cdot g+f \cdot \frac{\partial g}{\partial \gamma}\right)+f \cdot g \cdot \frac{\partial h}{\partial \gamma}\right] \\
& =h \cdot \lim _{\sigma \rightarrow \infty}\left(\frac{\partial f}{\partial \gamma} \cdot g+f \cdot \frac{\partial g}{\partial \gamma}\right)+g \cdot \frac{\partial h}{\partial \gamma} \cdot \lim _{\sigma \rightarrow \infty} f \\
& =-\frac{2 \tau_{\omega}}{1-\tau_{\pi}} \cdot h+g \cdot \frac{\partial h}{\partial \gamma} \cdot \infty \\
& =\infty \cdot \operatorname{sgn}\left[\frac{\partial h}{\partial \gamma}\right] .
\end{aligned}
$$

